Portland State University

PDXScholar

8-11-2020

\title{
Battle of the Buttercups: Investigating Hybrid Zone Dynamics in a Ranunculus Species Complex
}

Jessica Persinger

Portland State University

Follow this and additional works at: https://pdxscholar.library.pdx.edu/open_access_etds

Part of the Biology Commons

Let us know how access to this document benefits you.

\section{Recommended Citation}

Persinger, Jessica, "Battle of the Buttercups: Investigating Hybrid Zone Dynamics in a Ranunculus Species Complex" (2020). Dissertations and Theses. Paper 5578.

https://doi.org/10.15760/etd.7450

This Thesis is brought to you for free and open access. It has been accepted for inclusion in Dissertations and Theses by an authorized administrator of PDXScholar. Please contact us if we can make this document more accessible: pdxscholar@pdx.edu. 
Battle of the Buttercups: Investigating Hybrid Zone Dynamics in a Ranunculus Species Complex

\author{
by \\ Jessica Persinger
}

A thesis submitted in partial fulfillment of the requirements for the degree of

Master of Science

in

Biology

Thesis Committee:

Mitch Cruzan, Chair

Susan Masta

Sarah Eppley

Portland State University

2020 
(C) 2020 Jessica Persinger 


\begin{abstract}
Plants pose a well-known challenge to the biological species concept because hybridization is a common occurrence. Range dynamics have a crucial role in determining whether species are given the opportunity to interbreed or not. Successful hybridization can be of particular concern when considering rangelimited species and their persistence. In my thesis research, I examine the apparent hybrid zone between the southern Oregon endemic Ranunculus austrooreganus, a candidate threatened species due to its limited range, and its widespread congener, Ranunculus occidentalis, whose range spans from California to Alaska. The discovered contact zone was recognized in populations which contained apparent intermediate ventral petal coloration phenotypes. First, I utilized morphological quantification to understand phenotypic variation. Phenotype quantification based on ventral petal coloration and leaf trichome density have confirmed the presence of intermediate populations. Second, I confirmed extensive introgression through nuclear genome surveys with Genotyping-by-Sequencing despite structure analyses indicating the presence of two genetic subgroups. Third, 50 outlier loci were analyzed across geographic clines where results suggest the width of the hybrid zone spans $20 \mathrm{~km}$. Sampled populations of $R$. austro-oreganus and $R$. occidentalis display evidence of
\end{abstract}


extensive, ongoing gene flow and this species complex provides a unique example of genetic exchange between variable phenotypes. 


\section{Acknowledgements}

I would like to express great appreciation and thanks to the individuals who helped make my graduate education and thesis research possible. I first thank my thesis committee - my advisor, Dr. Mitch Cruzan, and Drs. Susan Masta and Sarah Eppley for their guidance, advice, and support. I would like to acknowledge Dr. Pamela Thompson for her recognition of the Ranunculus contact zone and thank her for her mentorship and research assistance. Additionally, thanks to all of my labmates - particularly Nic Diaz for his camaraderie throughout this journey; Tina Arredondo, Lizzi Hendrickson, Brendan Kohrn, Monica Grasty, and Jaime Schwoch for being around as graduate colleagues; and Ashley Hamilton, Hannah Machiorlete, Katie Kline, and Katie Gerloff for their help in the lab and field. Finally, I thank my family, friends, and my cat, Buddha, for their unwavering encouragement and support. This research was made possible with funding from the National Science Foundation. 


\section{Table of Contents}

Acknowledgements _ist of Figures




\section{List of Figures}

Figure 1. Sampling locations for the Ranunculus occidentalis (yellow), R. austrooreganus (orange), and their putative hybrids (green) in Jackson County, Oregon. The inset shows the geographic range of $R$. occidentalis in green and of R. austro-oreganus (small blue circle). Upper Table Rock (UTR) is labeled for reference. Page 26.

Figure 2. Morphological differentiation measured in the average gray values for petal color (A) and trichome density (B) in Ranunculus austro-oreganus, R. occidentalis, and their putative hybrids. Putative hybrids were found to be significantly intermediate between R. austro-oreganus and R. occidentalis populations for both ventral petal coloration and trichome density. Page 27.

Figure 3. The geographic distribution of populations of Ranunculus occidentalis (yellow markers), R. austro-oreganus (red markers), and their hybrids (orange markers) in Jackson County, Oregon showing the mean (marker color based on gray value) and the variance (marker size) in ventral petal color. Page 28.

Figure 4. The relationship between the mean and the variance in ventral petal color for populations of Ranunculus occidentalis (yellow markers), R. austrooreganus (orange markers), and hybrids (green markers) in Jackson County, Oregon. Page 29.

Figure 5 . The $\mathrm{K}=2$ minor cluster plot where sampled populations are organized across, west to east, the longitudinal geographic space of the putative hybrid zone. Page 30.

Figure 6. PCA generated with the R package adegenet and using the 2196 loci from GBS-SNP-CROP. Each dot represents a sequenced within a population and population identification is denoted by the color of the dot and ellipse surrounding the total population. PC 1 (x-axis) and PC 2 (y-axis) are displayed, as suggested by the corresponding eigenvalues. Page 31 .

Figure 7. Morphological geographic clines across the putative hybrid zone, longitudinally. These clines are based on morphological differences quantified in grayscale where $(A)$ displays ventral petal color and $(B)$ displays trichome density. Page 32. 
Figure 8. Histogram of estimated center of hybrid zone where the blue line indicates the average based upon significant cline models. Page 33.

Figure 9. Histogram of estimated width of hybrid zone where the blue vertical line indicates the average width value divided by two (+/- the center). The $x$ axes in the upper panels have been truncated for better visualization (Table B2). Page 34.

Figure 10. Populations whose nuclear DNA were analyzed. Hybrid zone center estimate (pink line) and width (green box) based on cline analyses is displayed. Page 35.

Figure 11. Number of loci pairs that were found to be in linkage disequilibrium in each population (black dots) across the putative hybrid zone. Page 36. 


\section{Introduction}

Understanding how to classify and define species is a fundamental question in evolutionary biology. Many concepts have been developed to delineate species, such as the biological species concept, where different species are defined as those that are unable to reproduce and make viable offspring (Mayr, 1942). Although the biological species concept is frequently used, a number of other species concepts have been deployed to better understand species classifications (e.g. phylogenetic, phenetic, ecological, genealogical). A number of challenges present when attempting to delineate species regardless of which concept is used, and species are notably more difficult to delineate when hybridization is ongoing. Hybridization has been defined as reproduction between genetically distinct populations (Barton and Hewitt, 1985), and when gene flow between species is ongoing these zones of contact can be understood as a genetic gradient between two species (Anderson, 1949). Major geological events, such as glaciations, create a unique opportunity for researchers to investigate lineages that have undergone divergence through glacial retreat. Geographically separated lineages have the potential to come back into proximity with one another and form hybrid zones (Mayr, 1963; Remington, 1968), allowing for observations in regard to species classifications. 
Since the early 1900 s, we have recognized the potential for hybridization to contribute to plant adaptation and diversification (Lotsy, 1916; Anderson, 1949; Anderson and Stebbins, 1954; Arnold, 1992; Rieseberg, 1997; Abbott et al., 2013), and hybrid zones provide an opportunity to document adaptive introgression (Taylor et al., 2015). Plants are ideal candidates for understanding congeneric species coexistence due to their limited capabilities for movement and dispersal and their ability to respond to microhabitat variation (Kay et al., 2016). The limited movement of plant populations creates a troubling scenario when it is predicted that they may need migrate up to $>1 \mathrm{~km}$ per year to continue living in an environment that is suitable as climate is changing (Corlett and Westcott, 2013). Plants can either adapt, migrate or die in response to a rapidly changing environment (Aitken et al., 2008), and hybrid zones provide an opportunity to document adaptive introgression (Taylor et al., 2015), which may be a solution that lineages will utilize in order to overcome a changing climate. Although gene flow may infuse populations with beneficial genetic variation, preventing excessive gene flow into populations of range-limited species from their widespread congeners is necessary for their continued independent divergence and eventual development of strong isolating barriers (Arnold, 1997; Sobel and Streisfeld, 2015). The ultimate fate of range-limited species will depend largely on the strength of isolating barriers and the dynamics of hybrid 
zones that may develop in regions of contact (Levin, 2003). Therefore, it is important to describe hybridization dynamics and patterns of gene flow in suspected hybrid zones to better understand species ecological and evolutionary trajectories.

Intermediate phenotypic forms have frequently been used to identify where species form a hybrid zone (e.g. Briggs 1962; Martin and Cruzan 1999; Gay et al., 2008; Morales-Rozo et al., 2017), and after a hybrid zone has been recognized, more detailed questions about gene flow and introgression between differentiated lineages can be investigated (Howard et al., 1997; Kay et al., 2018). Examining genomic differentiation and level of introgression between species in a hybrid zone provides an opportunity to disentangle the historical context of the species and better understand the longer-term outcomes of hybridization (Guichoux et al., 2013; Harrison and Larson, 2014). Hybridization between species can occur through historical gene flow, contemporary gene flow, or a combination of both. Genetic markers, most commonly singlenucleotide polymorphisms (SNPs), are often used to understand genetic variation (Petit et al., 2004) and are useful for understanding different time scales of gene flow. In order to utilize mitochondrial DNA (mtDNA) as a genetic marker in plants, a number of obstacles have had to be overcome (Palmer, 1992), but mtDNA has still been used in phylogenetic, phylogeographic, and population genetic studies 
(Puorto et al., 2001; Johnsen et al., 2017). Chloroplast DNA (cpDNA) markers have been preferred amongst plant scientists as the genome is highly conserved across species and does not recombine (Palmer, 1987) which enables studies regarding historical range dynamics (Heuertz et al., 2004). Nuclear DNA (nDNA) changes at a relatively fast rate due to genetic recombination, thus variants can provide detailed information about patterns of contemporary introgression and the dynamics of a hybrid zone (Barton and Hewitt, 1985). A recombining genome presents the opportunity to examine non-random associations of alleles on the same chromosome (linkage disequilibrium; LD) persisting through recombination events. LD estimates are higher when two distinct populations first hybridize and will consequently decay over time due to recombination effects (Reich et al., 2001).

Lineages can be characterized through the measurements of genomic diversity, and these data can inform the dynamics within a region of contact. Outlier loci, such as loci under selection, can be used to understand signatures of past introgression events throughout contact zones (e.g. Guichoux et al., 2013) and to understand the level of divergence that lineages may be experiencing. Outlier SNP data can then be used to measure allelic frequencies in populations, where large differences in allelic frequencies would suggest that selection is acting upon the genome. Changes in allele frequencies amongst populations is 
commonly viewed through cline analyses utilizing population genomic data (Qi et al., 2014; Stankowski et al., 2017; Esquerré et al., 2019; Scott et al., 2019), but can be carried out in a number of ways (Gompert et al., 2017). Geographic cline analyses are especially useful for integrating a spatial understanding of hybrid zones, allowing clines associated with both morphological and genomic data to be analyzed (Arntzen et al., 2016; Riemsdijk et al., 2019). Steep, narrow, and concordant clines would suggest a hybrid zone is being maintained by both strong selection and dispersal; conversely, gradual, wide, and displaced clines would indicate selection against hybrid individuals is low (Barton and Gale, 1993). Geographic cline data can then infer a directionality of a hybrid zone with the addition of LD analyses where asymmetrically higher levels of LD would suggest the hybrid zone would move in the direction of higher estimates (Wang et al., 2011).

\section{Study System}

In this study, I examine morphological and genomic variability between two perennial buttercups whose distributions and morphology suggests ongoing hybridization. The widespread species, Ranunculus occidentalis Nutt. (Western buttercup; Ranunculaceae), occurs across an extensive geographic region, stretching from southern California to Alaska, whereas Ranunculus austro- 
oreganus L.D. Benson (Southern Oregon buttercup) occupies a small range in Jackson County, Oregon and is considered a candidate threatened species (Fig. 1; Kagan et al., 2016). $R$. austro-oreganus was separated out from the $R$. occidentalis complex and described as a new species in 1954 (Benson) on the basis of its unique flower color, bulbous leaf bases, and a distinct geographic distribution. Both species are members of section Ranunculus within the genus (Benson, 1954); hybridization and incomplete barriers to crossing are common within sections of Ranunculus (Benson, 1948; Hörandl et al., 2005; Baltisberger and Hörandl, 2016). Analyses of chloroplast genomes confirm that $R$. austrooreganus and $R$. occidentalis are closely related (Li et al., 2019) and display evidence of historical gene flow (Appendix A). Additionally, greenhouse crosses between the two species have shown successful seed production and germination, indicating minimal barriers to reproductive success (unpublished data).

These two species appear to be interbreeding in a region where their ranges come into contact, in a narrow hybrid zone near the edge of a proposed suture zone in southern Oregon, USA (Swenson and Howard, 2004). These species have been found to occur in sympatry within similar ecogeographic regions. While the flowers of both species appear yellow from above, they are easily distinguished in the field based on the dark orange ventral petal color of $R$. 
austro-oreganus in contrast to the yellow ventral petals of $R$. occidentalis (Fig. 2A). Yellow petal coloration is associated with the presence of carotenoids and flavonoids (Grotewold, 2006; Ono et al., 2006), and the presence of an orange color indicates the additional presence of anthocyanins (Eugster and MärkiFischer, 1991; Berman et al., 2016). The putative hybrid zone was identified based on the presence of large numbers of plants displaying a range of ventral petal colors; this zone occupies a narrow region covering Upper Table Rock near Medford, Oregon (Fig. 1). Populations of the two species in the hybrid zone and allopatric populations in the region were sampled to confirm patterns of petal coloration and leaf trichome density measurements across the species' ranges in the Rogue River Valley. This information is supplemented with assays of nuclear genome variation to understand the putative hybrid zone dynamics.

Research conducted in the region suggests that past glaciation has greatly influenced the distribution of genetic variation of flora and fauna (Soltis et al., 1997). This species complex may be a product of divergent lineages from the last glacial maximum coming into secondary contact. It is possible that gene flow into populations of $R$. austro-oreganus from $R$. occidentalis would aid in adaptation depending on the cost of dispersal and the strength of genetic drift (Polechová, 2018) because of the limited range $R$. austro-oreganus occupies. It is also possible that these species are more recently diverged where the range- 
limited species has originated by budding (peripatric) speciation from $R$. occidentalis since the last ice age. It is worth noting that, in addition to the unknown historical context between these lineages, it is also unknown whether the hybrid zone between these populations is stationary or moving. Understanding the dynamics within this hybrid zone, or lack thereof, have implications for conservation biology when working with species that have limited ranges.

By quantifying phenotypic data and estimation of genomic variability in the putative hybrid zone, I will address the following questions: 1) what happens phenotypically when these two taxa come into contact, 2) what is the extent of the suspected hybrid zone, and 3) is there evidence of hybrid zone expansion? 


\section{Methods}

\section{Morphological Differentiation}

Observations of plants populations in the field and in the greenhouse suggested that Ranunculus austro-oreganus and Ranunculus occidentalis display differences in their ventral petal color and in the density of leaf trichomes. These two morphological traits were quantified across populations to characterize the geographic distribution of these traits across populations in the region of the presumed hybrid zone. Each population analyzed was assigned a species classification based on the apparent ventral petal coloration observed in the field. Three petals from three separate flowers and two leaves (one basal and one cauline) were collected in the field from each plant in two separate flowering seasons. Petals and leaves were collected in the field from 28 populations ( $6 R$. austro-oreganus, $11 R$. occidentalis, and 11 putative hybrids) in 2017 , and petals were collected from an additional two populations of $R$. austro-oreganus and two hybrid populations in 2019. Leaves and petals were placed in coin envelopes in the field and dried with silica beads.

Morphological characters were quantified using a Leica MZ16 stereomicroscope and ImageJ software (v.1.52c). Ventral petal color was quantified across 28 populations (a total of 532 individuals) by capturing images at $40 x$ magnification. ImageJ was used to convert each petal image to 8-bit gray 
scale using weighted RGB conversions to maintain luminosity $(R \times 0.30, G \times 0.59$, Bx0.11), where the yellow color is then perceived as lightness (high gray value) and the red/brown character is darkness (low gray value). A 500px² selection was made over the center of the image, with the goal of representing a section of the petal without any of the background in the selection. The ImageJ measurement tool was used to capture the mean gray-scale value of the selection, where every pixel had a value from 0 to 255, black to white. Variation in leaf hair coverage was quantified in the same manner as petals, for one basal and one cauline leaf from the 28 populations, resulting in 1,184 leaf samples. Each leaf image was converted to 8-bit gray scale and the mean gray-scale value was measured over a standardized area of $0.785 \mathrm{~mm}^{2}$ placed in the center of the leaf. Leaf and petal data were analyzed using linear models with SAS Proc GLM (2007) to test for differences between the three species classifications: the two Ranunculus species and the putative hybrid populations. Differences analyzed were conducted with sampling location nested within species/hybrid designations. The variance in ventral petal color (gray value) within populations was examined to assess the geographic distribution of hybrid populations. For leaf gray value analysis, leaf position was nested within species and location. Residuals from these models displayed approximately normal distributions. 


\section{DNA Isolation and Sequencing}

Leaf tissue was collected from 20 individuals in each of 48 populations from $R$. austro-oreganus, $R$. occidentalis, and their putative hybrids through the 2015-2018 field seasons. All plant material was stored in coin envelopes and were dried and kept in silica gel until DNA extraction. Total genomic DNA was extracted following the Qiagen DNeasy 96 Plant Kit protocol (Qiagen, Germantown, MD). Isolated DNA was quantified using a Qubit 4 fluorometer (Invitrogen, ThermoFisher Scientific, Waltham, MA), and purified DNA samples were stored at $-20^{\circ} \mathrm{C}$. Individuals with a DNA concentration greater than $20 \mathrm{ng} / \mathrm{ul}$ were prioritized and selected for Genotyping-by-Sequencing (GBS), a costeffective strategy for genome-wide variant discovery between restriction enzyme cut sites in nDNA (Elshire et al., 2011). To confirm DNA quality 100ng of DNA for $10 \%$ of samples were digested with EcoRI (GAATTC) and incubated at $37^{\circ} \mathrm{C}$ for 2 hours. Digested and undigested samples were then run in separate lanes on a $1 \%$ agarose gel for 60 minutes and imaged to confirm digest success. DNA isolations from $125 R$. austro-oreganus, $174 R$. occidentalis, and 79 putative hybrid individuals $(16,22$, and 10 populations respectively, ranging from 7-8 individuals per population) were chosen to be sequenced. Four 96-well plates, each containing a blank for control, were submitted on dry ice to the Biotechnology Center at University of Wisconsin-Madison for enzyme 
optimization, library construction, and sequencing (HiSeq 1x100, 96 samples per lane). Enzyme optimization indicated that ApeKI (GCWGC) would be most effective and was subsequently used to prepare all GBS libraries.

GBS data were filtered for a minimum quality and analyzed for genotyping using a mock reference to identify variants. Sequencing data was processed with GBS-SNP-CROP v.4.0 (Melo et al., 2016), a bioinformatic pipeline utilized to implement quality control, generate a mock reference, and genomic variants were identified. All computing processing was carried out using the Coeus High Performance Computing (HPC) cluster at Portland State University. The four plates of GBS data were quality filtered, trimmed, and demultiplexed separately. Reads were trimmed and quality filtered using Trimmomatic (Bolger et al., 2014) and trimmed according to the following guidelines: their average quality score dropped below 30 in a 4bp sliding window, leading and trailing bases were trimmed if their quality score dropped below 30 , and any reads following trimming with a length under 32bp were discarded. Seven individuals without sufficient data (<200KB file size) were removed at this stage, four blank wells and three individuals.

The mock reference was created by finding a consensus between two individuals collected from populations classified as $R$. occidentalis that were suspected to be outside of the putative hybrid zone based on petal coloration 
(populations 'OldStageRd1' and 'OldStageRd2'); two individuals were used to reduce erroneous reads in the mock reference. The VSEARCH clustering algorithm (Rognes et al., 2016) was used for reads that were above the $93 \%$ nucleotide identity cutoff and the minimum acceptable length for a mock reference cluster was $32 \mathrm{bp}$. All 377 individuals were then aligned to the mock reference through the use of BWA-mem (Li and Durbin, 2009). Variant SNPs were recognized through the use of SAMtools (Li et al., 2009) where a minimum acceptable phred score base call quality and alignment quality of 30 was required. A variant discovery matrix was then created by identifying SNPs between the mock reference and all individuals used. The variant discovery matrix was then filtered with the following parameters, as recommended for diploid data in the GBS-SNP-CROP pipeline (Melo et al., 2016): a minimum of $75 \%$ of individuals needed to have the variant present with an average read depth ranging from 3-200 and a minimum of three individuals supporting the existence of an alternate allele. Non-primary allele reads were removed if the secondary allele percentage was below $80 \%$ across all individuals. The read depth required to call an individual a homozygote when the secondary allele depth was equal to zero was a minimum of 5 reads. If there was a secondary allele present the minimum read depth was 20 in order for an individual to call the individual homozygous, with a minimum ratio of primary to alternate reads of 0.3 . 
SNPs with a proportion of heterozygous individuals greater than 0.5 or a minor allele frequency below 0.05 were then removed with TASSEL (Bradbury et al., 2007) as these were likely a result from misalignment or a collapse of homologous regions in the mock reference, consequently not representing true variants. Once filtered, a subset of 2196 SNPs remained and were used in subsequent analyses.

\section{Genetic Clustering}

I analyzed genetic clustering and structure in a variety of ways to understand the separation of allelic frequencies among populations. Population heterozygosity and SNP frequency measurements were estimated with Adegenet v.2.1.0 in R (Jombart, 2008). A PCA matrix of individuals' genotype frequencies was constructed using Hierfstat (Fig. 4; Goudet, 2005). Genetic clusters were estimated using a Bayesian framework with the program Structure (Pritchard et al., 2000). The number of possible subpopulations (K) was estimated by examining $K$ values ranging from $1-23$, each having ten replicates containing a burn-in of 25,000 and MCMC of 25,000. Options to "use sampling locations to assist clustering (locprior model)" and "use given populations at the initial condition for population origins (start at pop info)" were flagged to improve the model. The optimal $\mathrm{K}$ was found using the Evanno method (Evanno et al., 2005) 
and CLUMPAK (Kopelman et al., 2015) assisted in the visualization of the Structure output.

\section{Outlier Loci}

Loci potentially affected by selection pressures (i.e. divergent selection, genetic hitchhiking) can aid in the estimation of hybrid zone clines by indicating genetic structure (Nosil et al., 2009; Gompert and Buerkle, 2011). The outlier loci that may be under selection cam be especially useful for assessing differences in relative gene flow when gene flow is high (Guichoux et al., 2013), as suspected in the two Ranunculus species. Outlier loci are typically identified through tests of genetic differentiation (e.g. Fst) that is higher than expected under a neutral distribution (Beaumont and Balding, 2004). Fst estimates using BayeScan v2.1 (Foll and Gaggiotti, 2008) failed to identify outlier loci in this system. Alternatively, outlier loci were identified through the use of morphological differentiation by analyzing four populations, two $R$. austro-oreganus and two $R$. occidentalis, based on their lowest variance populations and ventral petal color measurements. These four populations are suspected to have the least amount of introgression given their phenotypic measurements. Outlier loci in this study were identified and defined as SNPs with moderate allelic frequency differences $(>0.3)$ between the two groupings populations, suggestive of ongoing 
interspecific genetic differentiation. Additional SNPs were identified as being outlier loci with the requirement of putative species classifications having moderate allelic frequency differences ( $>0.3$ ) between all $R$. austro-oreganus and R. occidentalis populations. These criteria identified a total of 61 outlier SNPs out of the original 2196 detected.

\section{Geographic Cline Analysis}

Geographic clines can be used to understand the dynamics in a hybrid zone for different traits and genetic parameters. Steep clines across a study region would suggest that the characters examined are under selection pressure, whereas gradual clines would indicate weak selection. Cline estimation was carried out using a maximum likelihood approach for both of the morphological traits and each of the 61 outlier loci. These data were analyzed across a single latitudinal geographic distance where a population location's latitude was putatively found to be the "center" of the hybrid zone (population UTR9). Population distance to the center of the hybrid zone was found by utilizing each longitude value and measuring to the center on a projected latitude line using ArcMap v.10.7.1 (Table B1; ESRI, Redlands, CA). Cline models were estimated with the R package HZAR (Derryberry et al., 2014); grayscale measurements for each populations' petal color and trichome density along with allelic frequency at 
each locus were assessed. A null model, which tests the hypothesis that there is no cline in the sampled region, along with 15 alternative cline models were analyzed for each locus. Each model was run on a separate seed and were run with a MCMC length set to 100,000 with a burn-in of 10,000 . All cline models were checked for convergence and the best-fit model (lowest AIC score) was selected to extract summary statistics and the maximum-likelihood clines for each variant. Cline center and width were then estimated by averaging the statistics from the significant outlier loci cline models.

\section{Linkage Disequilibrium}

The nuclear genome undergoes recombination during meiosis which allows for linkage disequilibrium estimates to identify populations that have been subjected to recent introgression. The 50 loci that were found to have significant geographic cline models were selected to be analyzed, as these were loci most differentiated across the study region and would likely show traces of LD in hybrid populations. The 50 loci were gathered from the raw VCF file output from GBS-SNP-CROP and were converted to an Arlequin input file (PGDSpider v.1.1.5; Lischer \& Excoffier, 2012) where the data were organized at the population level. Linkage disequilibrium analyses were then conducted in Arlequin v.3.5 (Excoffier and Lischer, 2010). The loci were treated as genotypic 
data with the gametic phase known. 10,000 steps in Markov Chain were run along with 100,000 dememorization steps between pairwise loci. Total counts of pairwise loci in each population that were found to be in significant linkage disequilibrium were summarized to be compared across geographic space. 


\section{Results}

\section{Morphological Variation}

Strong differences were found between the two Ranunculus species and the putative hybrid populations for two phenotypic traits: ventral petal color, as anticipated by field observations, and leaf trichome density, a variable trait first

discovered and described by this research. Ventral petals of $R$. austro-oreganus were much darker compared to $R$. occidentalis, and hybrids were intermediate $\left(F_{2 / 25}=61.36, P<0.0001 ;\right.$ Fig. 2$)$, as expected due to the use of the trait to define species and hybrids. Leaves of $R$. austro-oreganus were much brighter (denoting more leaf trichomes) than R. occidentalis, and the hybrids were intermediate between the two species $\left(F_{2 / 25}=5.03, P=0.0146\right.$; Fig. 2). There were significant differences among sampling locations for petal gray values $\left(F_{25 / 501}=14.79, P<0.001\right)$ and leaf hair gray values $\left(F_{25 / 28}=21.52, P<0.001\right)$. The difference for gray value between basal and cauline leaves was not significant $\left(F_{28 / 1005}=0.78, P=0.793\right.$ for leaf position nested within species*location tested over the error).

The variance in ventral petal color corresponds with the location of the putative hybrid zone (compare Figs. 1 and 3), but there is also evidence of highly variable measurements in populations of $R$. austro-oreganus at the southeastern edge of its range (Agate Lake; Fig. 3). Overall, there was a strong 
correspondence between the mean ventral petal color and the variance in color (based on gray scale) which was anticipated by the field observations that led to each population's species classification. Populations having intermediate coloration display the highest variance in color (Fig. 4; quadratic model adjusted $\left.R^{2}=0.66, F_{2 / 27}=29.2, P<0.0001\right)$.

\section{Nuclear DNA}

After filtering, the GBS-SNP-CROP pipeline identified 2196 variants among 377 individuals in comparison to the consensus mock reference. The largest peak in the Delta $\mathrm{K}$ value from the Structure analysis indicates $\mathrm{K}=2$ as the optimum number of genetic clusters; a second peak in the Delta $\mathrm{K}$ value is present at $\mathrm{K}=11$ (Fig. B1). The subpopulation structure of $\mathrm{K}=2$ does not show distinct differences across the geographic space (Fig. 5), although a trend of increasing admixture is apparent in eastern populations. Western populations, largely composed of $R$. occidentalis, display strong population structure. Similarly to the structure analysis, the PCA suggests that there is a separation into two groupings (Fig. 6), although there is separation occurring within populations. PC 1 explains $2.51 \%$ of the genetic variation and PC 2 explains $2.24 \%$. There was a steep decline in eigenvalues for the remainder of the principal components. 
The four populations used to identify outlier loci revealed 56 loci of interest for cline analyses (Table B2). An additional seven loci, two of which overlapped with the allopatric SNP subset, were additionally identified to be outlier loci of interest due to moderate allelic frequency differences found between all $R$. austro-oreganus and $R$. occidentalis populations (Table B2). A total of 61 variants were classified as outlier loci and used for cline analyses. Geographic clines estimated for morphological traits and nuclear loci displayed varying results. Petal color and trichome density showed highly differentiated clines, where petal color shows a steep cline near the proposed center of the hybrid zone and trichome density shows a gradual change over geographic space (Fig 7). Of the 61 outlier loci examined, 50 loci were found to have significant cline models (Fig. B2) with variable cline center and width estimates (Table B2). The average cline center was estimated to be 2710 meters East from the proposed center (Fig. 8) and the average cline width was estimated to be 19696 meters (+/- 9848 meters from the center; Fig. 9; Table B2). The estimated hybrid zone spans the entirety of the morphological sampling extent (Fig. 10). Total counts of significant pairwise loci found to be in linkage disequilibrium showed a general trend of increasing across the putative hybrid zone geographic space (Table B1; Fig. 11). to be compared across geographic space. 


\section{Discussion}

In this study, a combination of morphological characters and DNA analyses were used to characterize variation across a contact zone between two buttercups, $R$. austro-oreganus and $R$. occidentalis. Image analyses of petal coloration confirmed that there are intermediate phenotypes in suspected hybrid populations, a common occurrence in hybrid zones (Kálmán et al., 2004). Leaf trichome density analyses were additionally discovered to support the intermediate population measurements and classifications. Populations were identified based on ventral petal coloration during field collections and the image analysis confirms those groupings. However, populations classified based on the prevalent phenotypes display evidence of extensive introgression of nuclear loci based upon GBS analyses. Additionally, intermediate trichome density measurements support the differentiation in species classifications as we did not categorize species based on this trait; trichome density of the suspected hybrid populations is significantly different from both $R$. occidentalis and $R$. austrooreganus. The geographic clines resulting from the morphological analyses indicate considerable evidence that both traits vary across this hybrid zone. The cline derived from ventral petal color data displays a very steep cline shape suggesting that selection is strongly acting upon this trait. Floral traits under selection have been found to be associated with ecotypic variation (Stankowski 
et al., 2017) and this possibility must be considered for this system. On the other hand, trichome density has a much more gradual cline shape suggesting weaker selection, although leaf traits are also known to be involved in ecotypic variability (Kay et al., 2018).

The morphological characters observed in the study are both known for their adaptive importance. It was hypothesized that the darker ventral petal coloration may be derived from anthocyanins, which are known for ultraviolet radiation protection (Mori et al., 2005). Additionally, petal variation may be driving pollinator preferences (Meléndez-Ackerman, 1997; Pansarin and Amaral, 2008; Anderson et al., 2009) which could influence selection pressures. The increase in trichome density in $R$. austro-oreganus also has the potential to contribute against ultraviolet radiation (Karabourniotis et al., 1992; Skaltsa et al., 1994). An increase in trichome density can additionally increase the leaf boundary layer, thus decreasing leaf temperature and diffusion of both water vapor and carbon dioxide (Ehleringer and Mooney, 1978). A reduction in transpiration rate can lead to higher leaf temperatures because the leaves are less able to cool themselves (Ripley et al., 1999), although abundant trichomes may aid in drought stressed plants by absorbing water and decreasing adverse drought related effects (Grammatikopoulos and Manetas, 1994). R. austro-oreganus may be considered more fit for a changing climate because it contains both adaptive traits (darker 
petal coloration and higher trichome density) which may be due to a historical range where these traits were favored (i.e. higher elevation, higher UV radiation exposure, less rainfall, etc.).

We identified a contact zone between two Ranunculus species, located in Medford, Oregon. The contact zone is composed of two genetic clusters where there is a substantial level of shared variation among the 2196 nuclear SNPs identified. These results fail to provide a clear separation of genetic clusters between these two species, signifying extensive admixture. This study system exemplifies far more admixture and less population structure than other hybridization studies conducted in a similar spatial extent (e.g. Zamudio and Wieczorek, 2007; Sung et al., 2018). There is a second peak in Delta K values suggesting that substructure exists within the two genetic clusters and may be present in response to ecotypic differences (Andrew and Rieseberg, 2013). The second peak in Delta $\mathrm{K}$ values should be strongly considered given the known tendency for structure analyses to suggest $K=2$ (Janes et al., 2017). The principal components analysis displayed similar results to the structure analysis, where the first two principal components described the most genetic variations at approximately $4.75 \%$. Western populations, largely composed of $R$. occidentalis, appear to contain less genetic variation amongst individuals sequenced. 
Cline models derived from 50 nuclear SNPs display varying steepness, where steeper clines suggest selection acting upon those genomic regions. Estimation of the cline center confirms field observations where the center occurs east of Upper Table Rock and the width of the hybrid zone spans the entirety of the longitudinal sampling area used for the morphological analyses. The longitudinal sampling scheme implemented in this study may be misleading to the estimates of the hybrid zone. It is possible that the geographic distance parameter could be fine-tuned to better represent species distributions to better disentangle population structure that may exist. Changes to the distance parameter could change both the center and width estimates, but the inference of ongoing gene flow would not change. Structure analyses, hybrid zone extent estimates, and linkage disequilibrium counts all suggest that $R$. austro-oreganus populations are experiencing extensive gene flow with $R$. occidentalis. This could have long-term implications for the range-limited species, as its range may become furtherly limited. Although the fate of the range-limited species is dim, it's possible that the adaptive traits that $R$. austro-oreganus exhibit will provide hybrid vigor to populations in this contact zone (Anderson and Stebbins, 1954). 


\section{Conclusions}

In summary, evidence of a hybrid zone has been found between the widespread buttercup species, $R$. occidentalis, and the range-limited $R$. austrooreganus. The data reported in this study are virtually the only information available on the biology of $R$. austro-oreganus, which is being considered for threatened species listing (Kagan et al., 2016). The phenotypic patterns provide support for the presence of intermediate populations, where selection appears to be acting upon ventral petal coloration. Furthermore, geographic clines display evidence of a hybrid zone spanning $20 \mathrm{~km}$ across Jackson County, Oregon, where selection appears to be acting upon phenotypic traits along with a number of genomic loci as indicated by steep clines. Linkage disequilibrium analyses indicate that the hybrid zone is moving east towards the range-limited species. Genetic analyses suggest extensive contemporary introgression throughout the contact zone. Depending on the historical relationship between these species, the movement of the hybrid zone could suggest: 1 . that the range-limited species will continue to experience genetic swamping by its widespread congener, or 2 . the range-limited species is expanding its range into that of its widespread congener. Further analyses are required to fully understand the dynamics of this contact zone. 
Results of future work could be improved by incorporating genomic information and abiotic factors in an ecological niche modeling approach to evaluate intra-specific response and local adaptation to environmental factors (e.g. Swenson, 2006; Barnard-Kubow et al., 2015; Fitzpatrick and Keller, 2015). Abiotic factors such as soil composition, annual rainfall, elevation, and local temperatures may be influencing the ranges that these populations are well adapted to and may be maintaining phenotypic differentiation. Given that these species apparently may possess distinct, separate adaptations to the same environment, they may also have varying responses to climate change, anthropogenic stressors, and hybridization event outcomes. Future work expanding on greenhouse crosses between the species and experimental common garden studies have great potential to contribute to our understanding of the abiotic variables promoting growth in each species. Additionally, future studies could focus on investigating the potential association between genomic and phenotypic data to better understand traits potentially important in reproductive isolation and/or adaptive introgression (e.g. Sung et al., 2018). The Ranunculus species complex presented here should be considered a strong candidate system for better understanding contact zones that could have important implications for directing conservation efforts, especially in the case of range-limited species. 


\section{Figures}

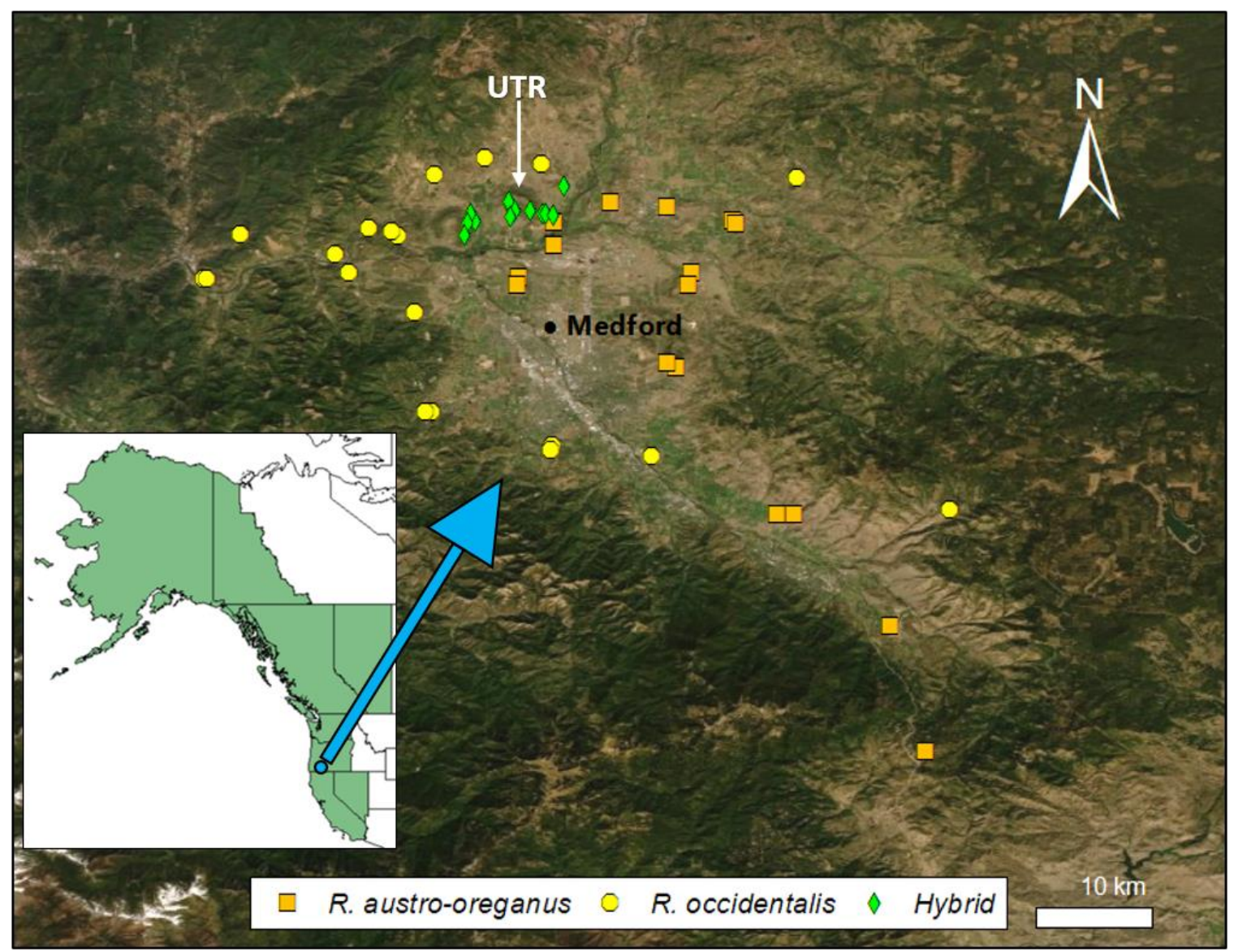

Figure 1. Sampling locations for the Ranunculus occidentalis (yellow), R. austrooreganus (orange), and their putative hybrids (green) in Jackson County, Oregon. The inset shows the geographic range of $R$. occidentalis in green and of R. austro-oreganus (small blue circle). Upper Table Rock (UTR) is labeled for reference. 

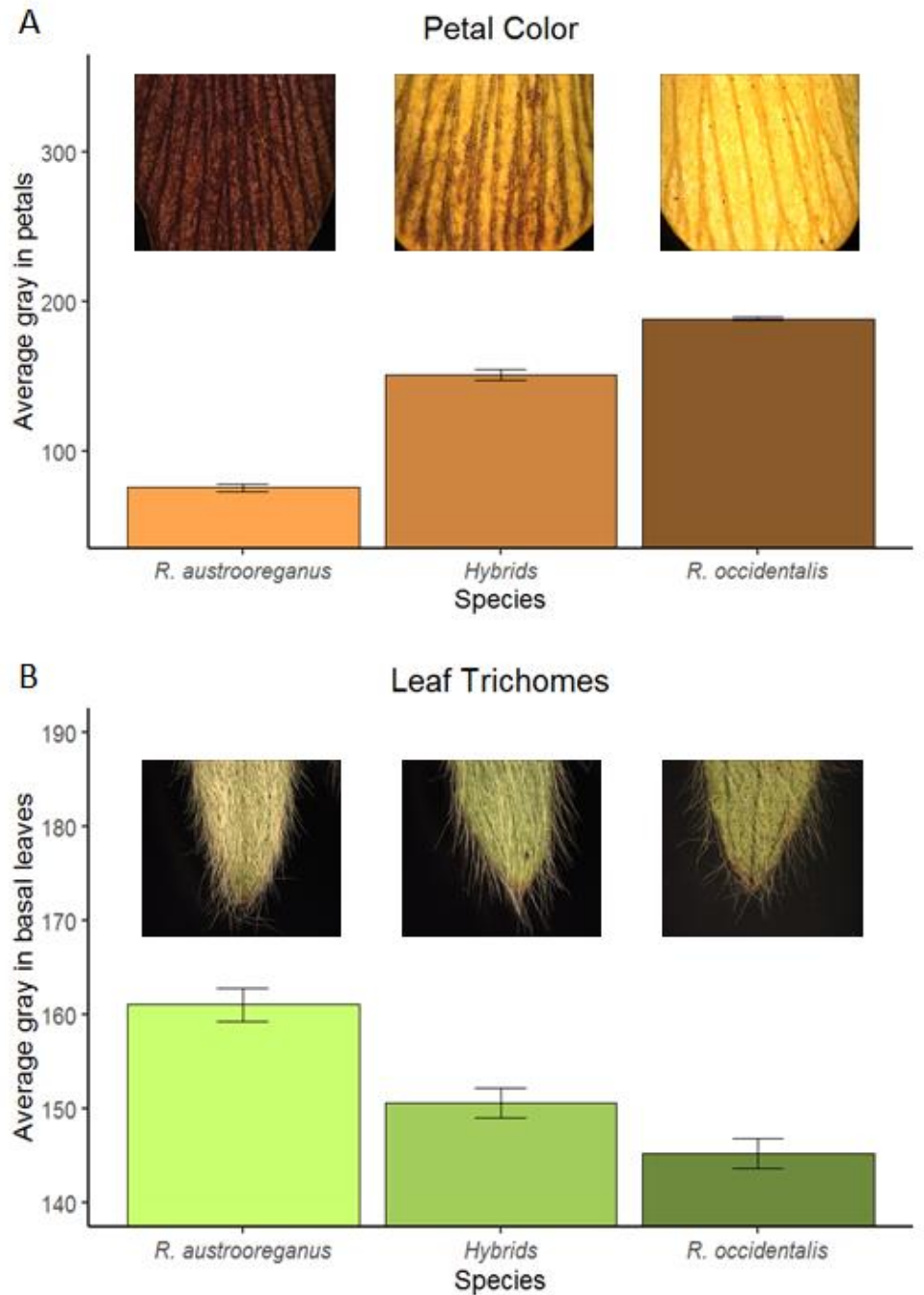

Figure 2. Morphological differentiation measured in the average gray values for petal color (A) and trichome density (B) in Ranunculus austro-oreganus, $R$. occidentalis, and their putative hybrids. Putative hybrids were found to be significantly intermediate between $R$. austro-oreganus and $R$. occidentalis populations for both ventral petal coloration and trichome density. 


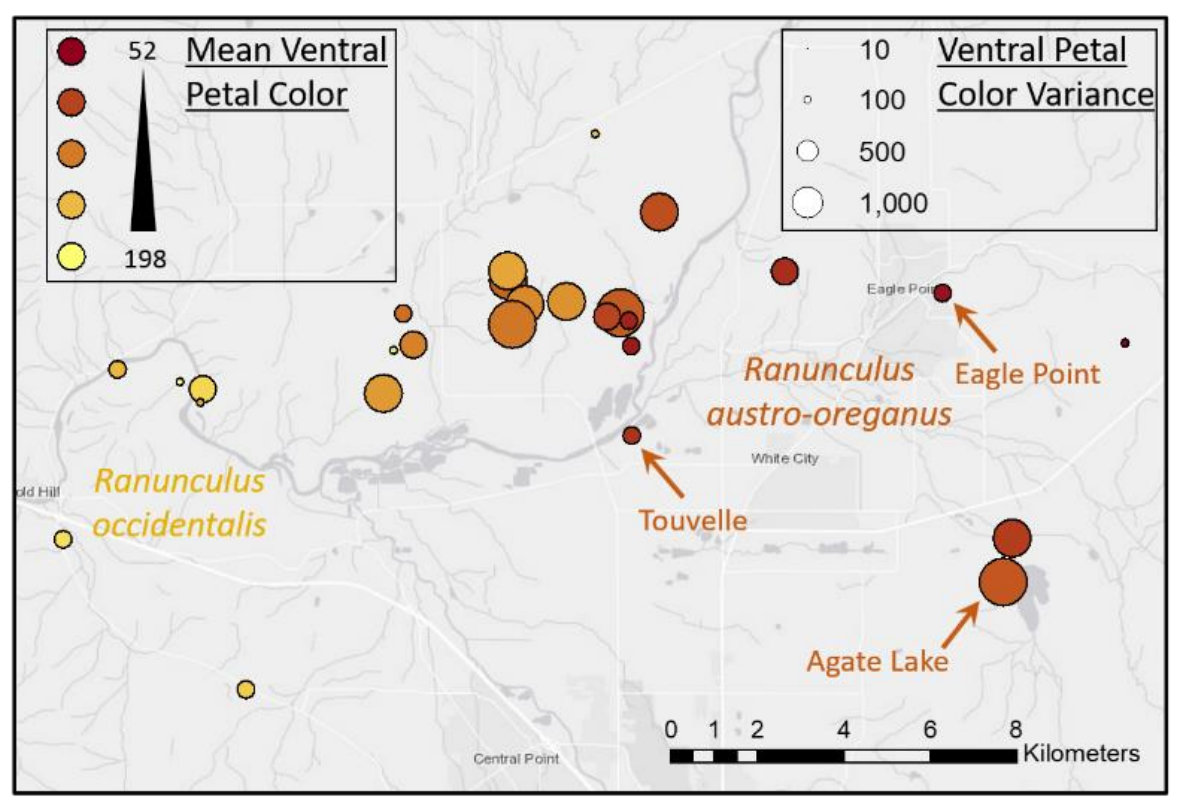

Figure 3. The geographic distribution of populations of Ranunculus occidentalis (yellow markers), R. austro-oreganus (red markers), and their hybrids (orange markers) in Jackson County, Oregon showing the mean (marker color based on gray value) and the variance (marker size) in ventral petal color. 


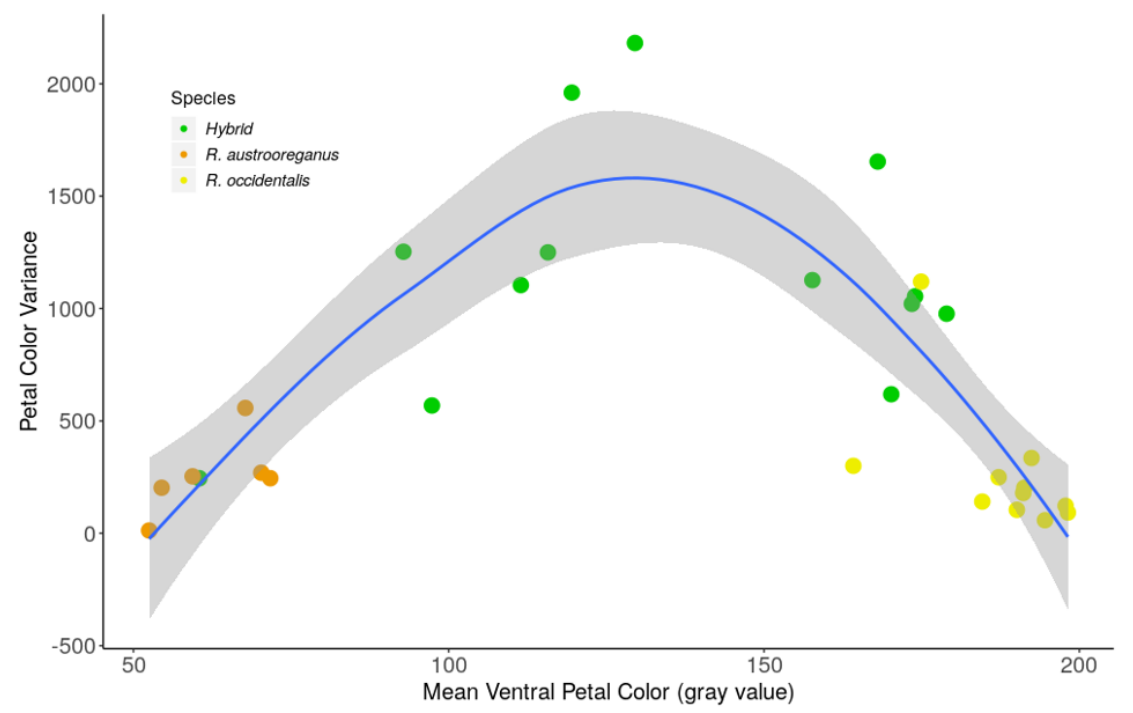

Figure 4. The relationship between the mean and the variance in ventral petal color for populations of Ranunculus occidentalis (yellow markers), R. austrooreganus (orange markers), and hybrids (green markers) in Jackson County, Oregon. 


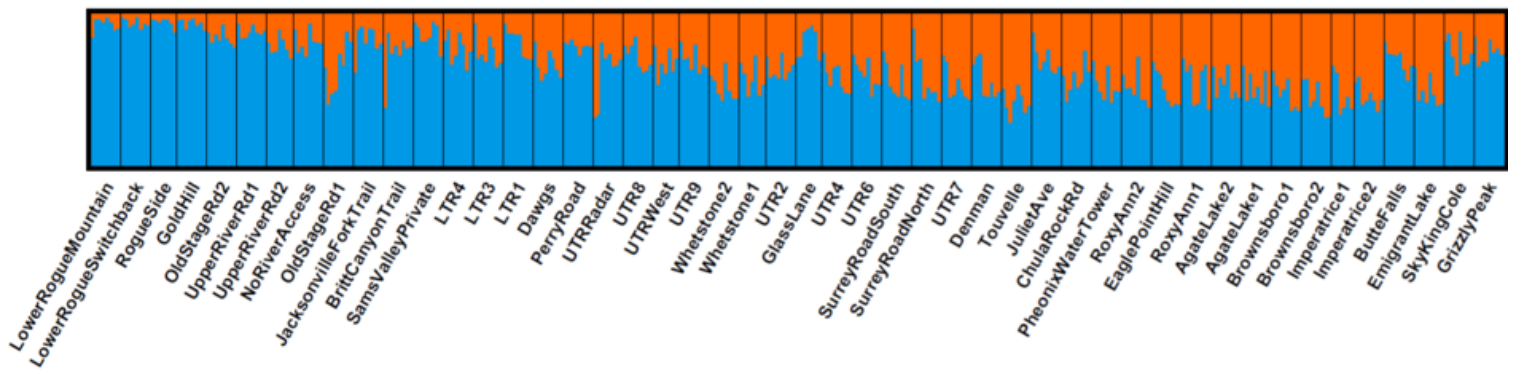

Figure 5. The $\mathrm{K}=2$ minor cluster plot where sampled populations are organized across, west to east, the longitudinal geographic space of the putative hybrid zone. 


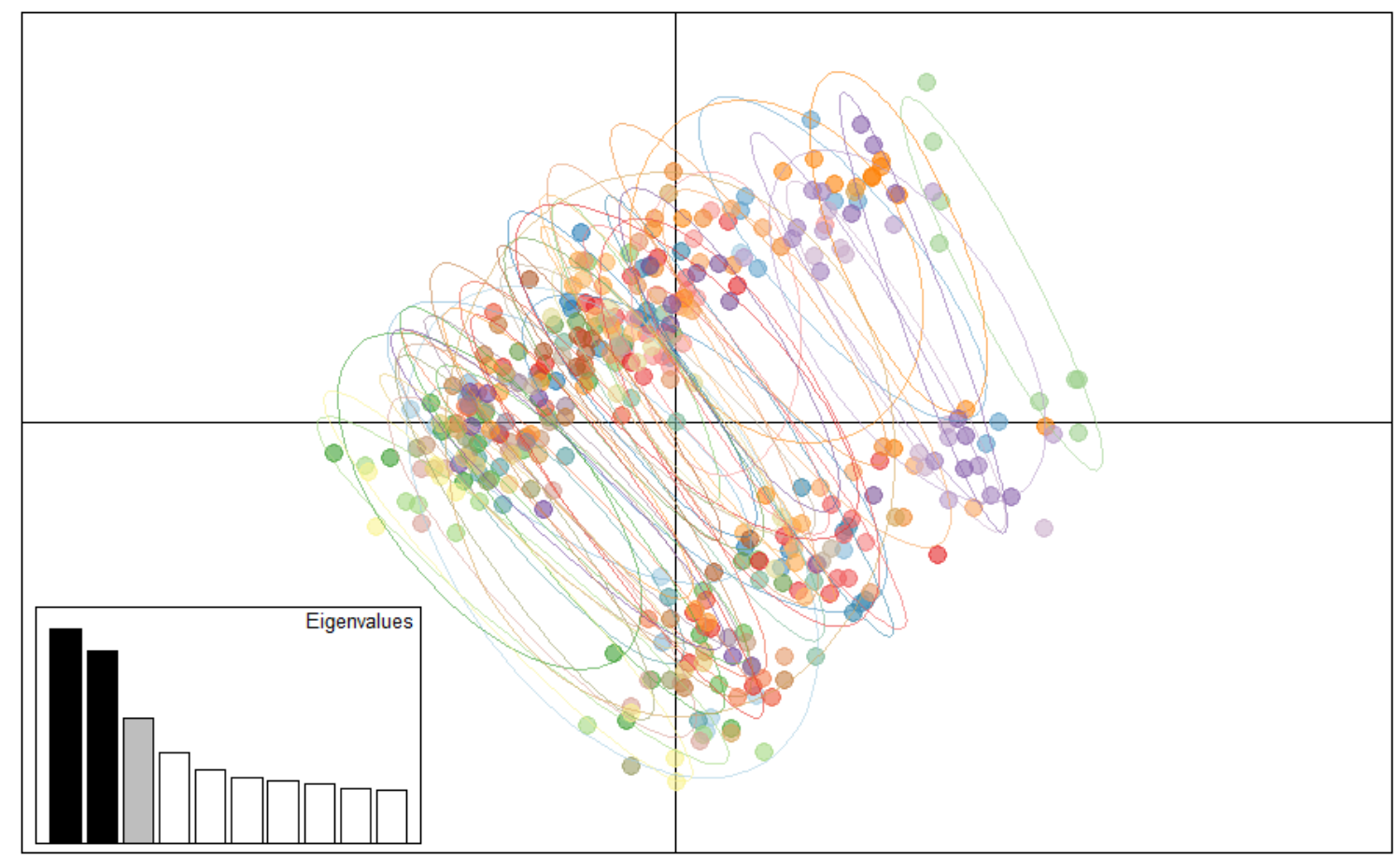

Figure 6. PCA generated with the R package adegenet and using the 2196 loci from GBS-SNP-CROP. Each dot represents a sequenced within a population and population identification is denoted by the color of the dot and ellipse surrounding the total population. PC 1 (x-axis) and PC 2 (y-axis) are displayed, as suggested by the corresponding eigenvalues. 

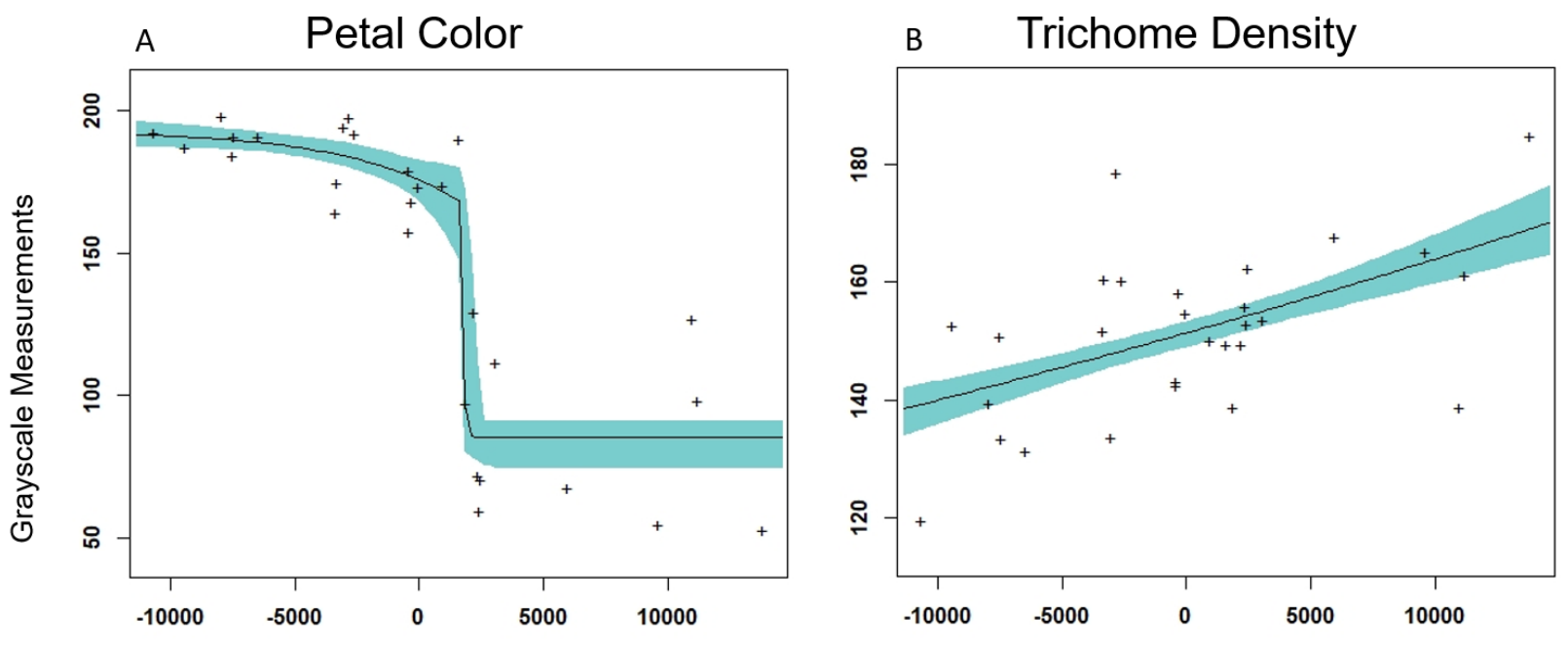

Geographic Distance (m) from Hybrid Zone

Figure 7. Morphological geographic clines across the putative hybrid zone, longitudinally. These clines are based on morphological differences quantified in grayscale where $(A)$ displays ventral petal color and $(B)$ displays trichome density. 


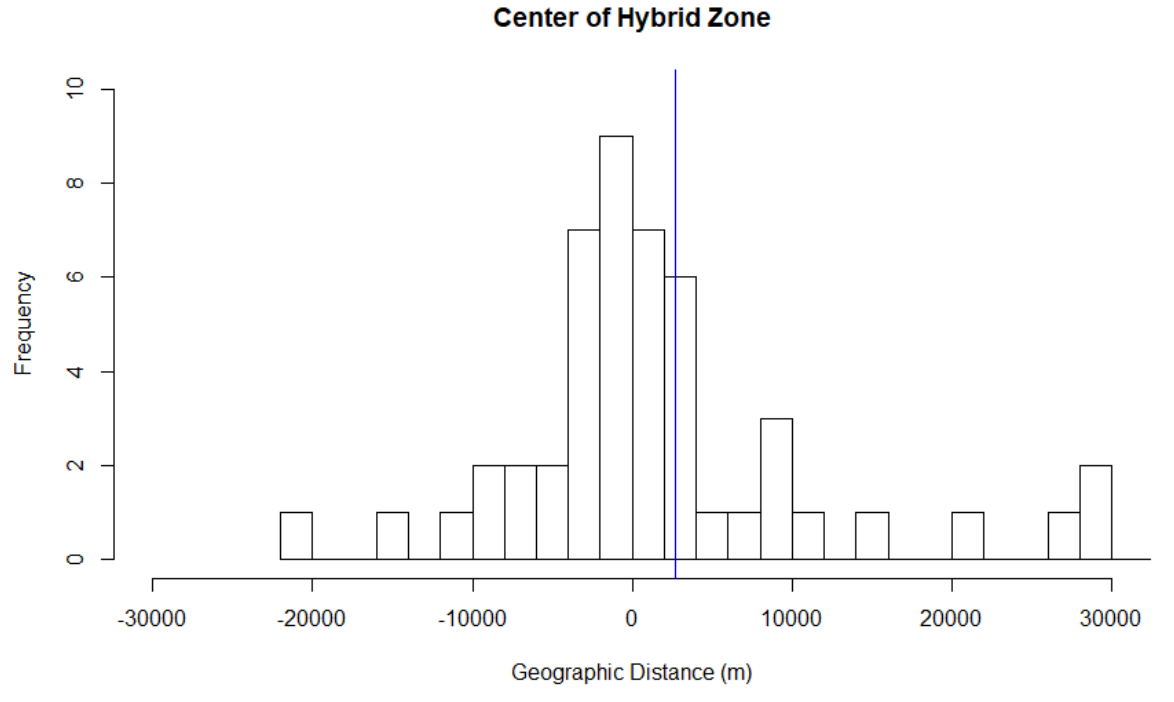

Figure 8. Histogram of estimated center of hybrid zone where the blue line indicates the average based upon significant cline models. 


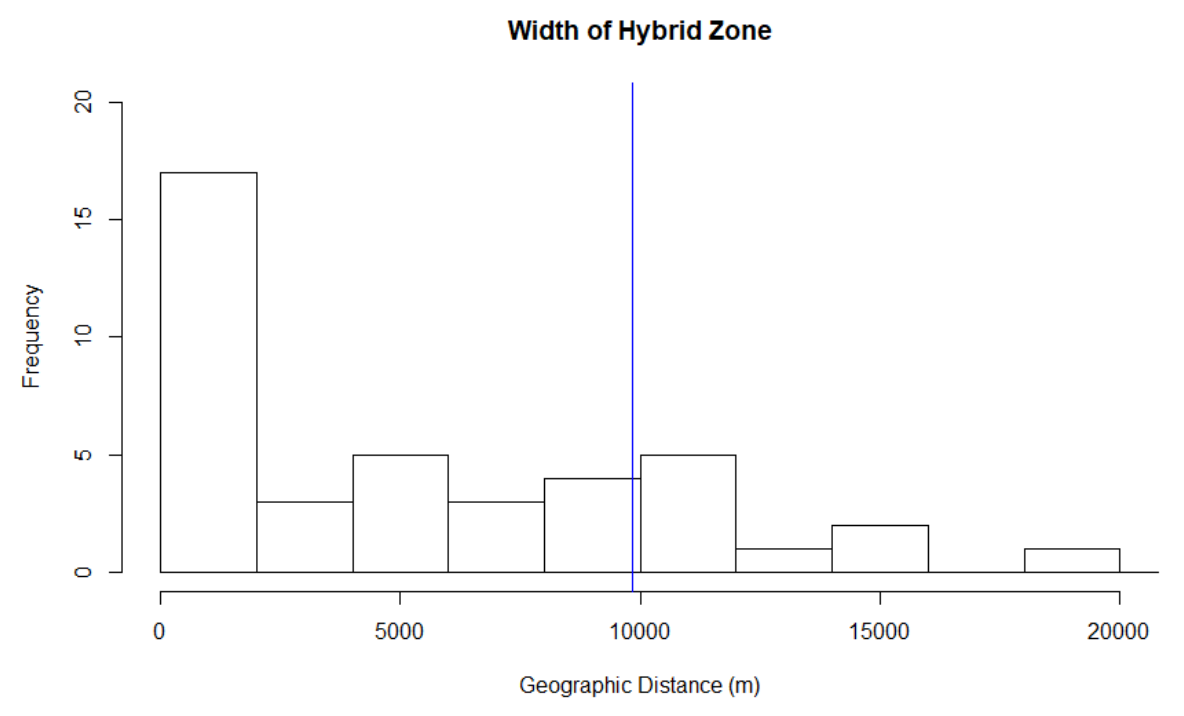

Figure 9. Histogram of estimated width of hybrid zone where the blue vertical line indicates the average width value divided by two (+/- the center). The $x$ axes in the upper panels have been truncated for better visualization (Table B2). 


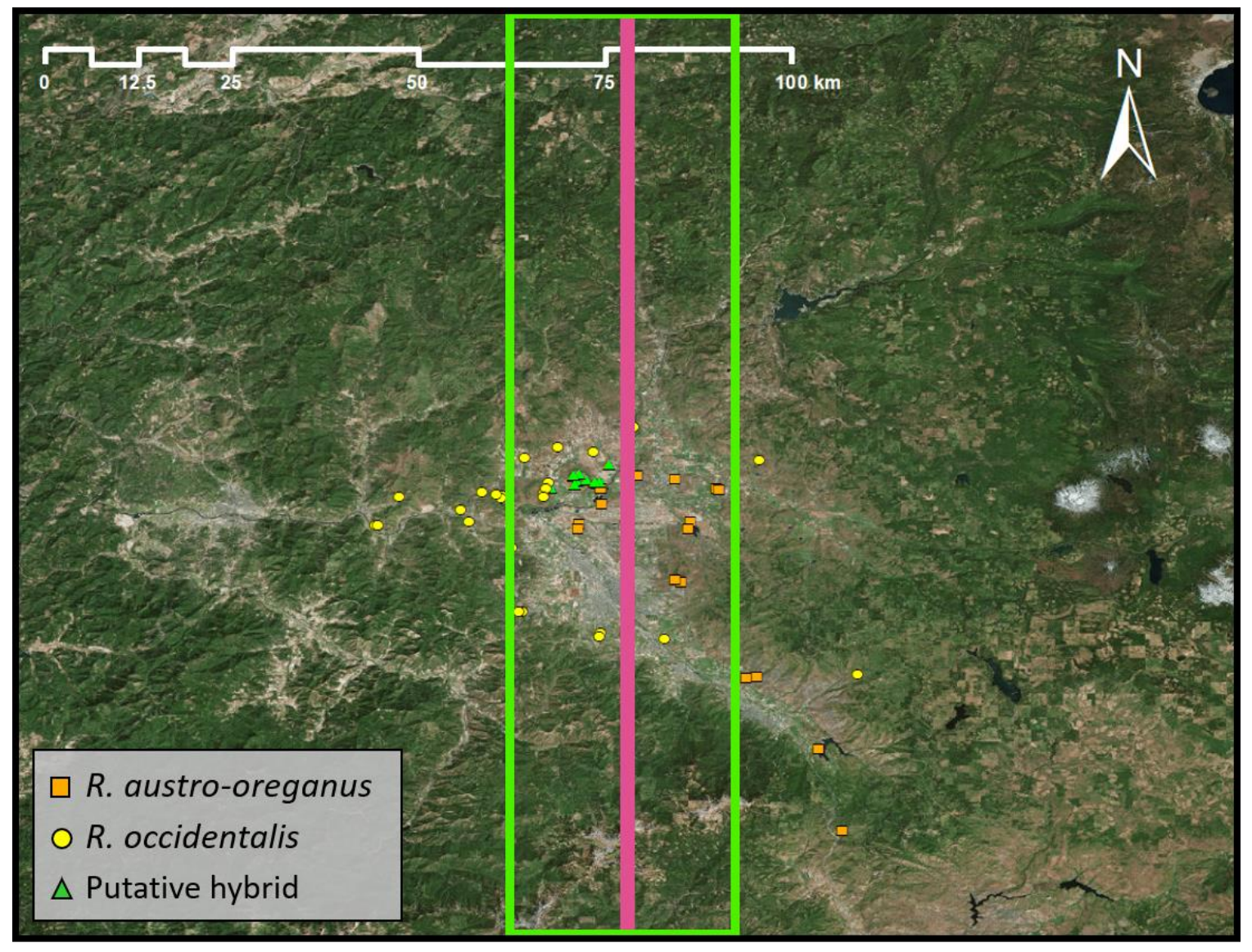

Figure 10. Populations whose nuclear DNA were analyzed. Hybrid zone center estimate (pink line) and width (green box) based on cline analyses is displayed. 


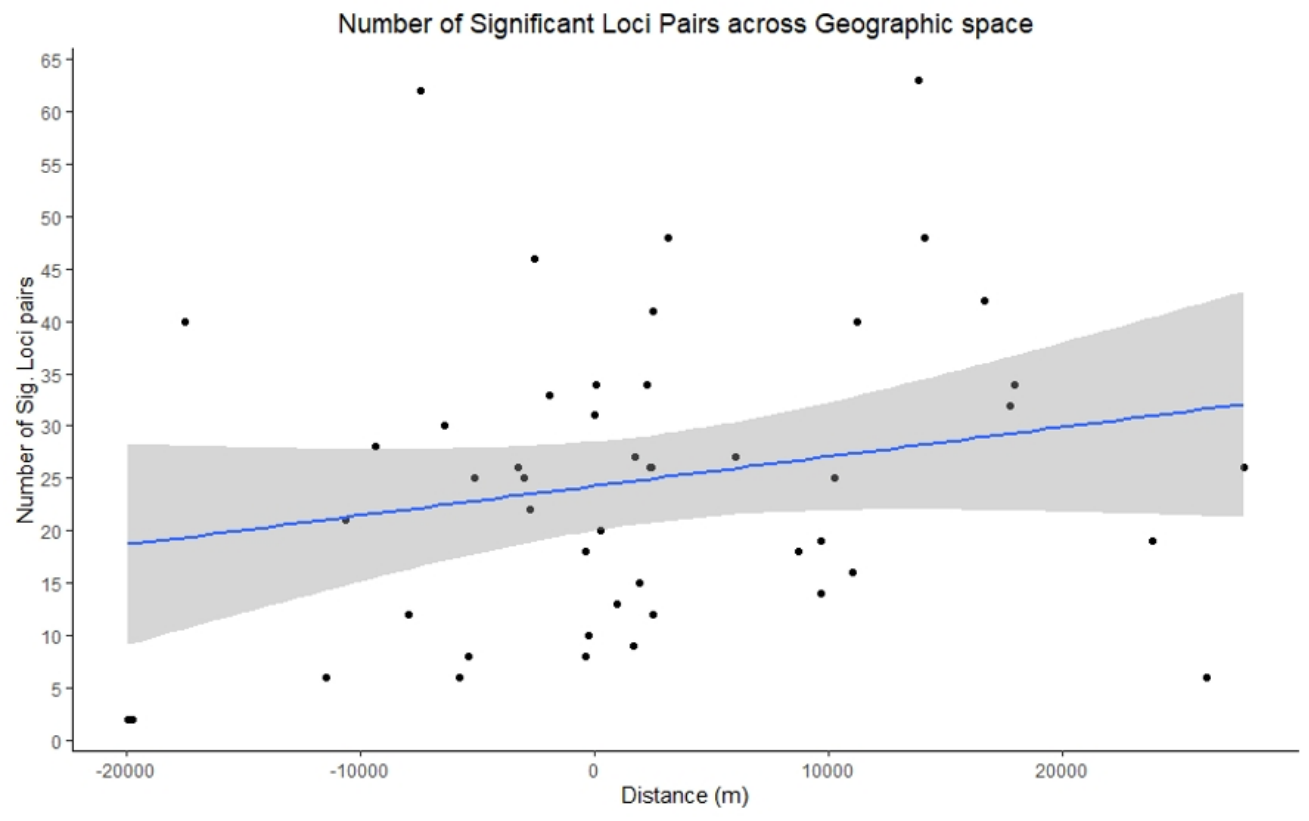

Figure 11. Number of loci pairs that were found to be in linkage disequilibrium in each population (black dots) across the putative hybrid zone. 


\section{References}

Abbott, R., Albach, D., Ansell, S., Arntzen, J.W., Baird, S.J.E., Bierne, N., et al. 2013. Hybridization and speciation. J. Evol. Biol., 26: 229-246. Wiley/Blackwell (10.1111).

Aitken, S.N., Yeaman, S., Holliday, J.A., Wang, T. and Curtis-McLane, S. 2008. Adaptation, migration or extirpation: climate change outcomes for tree populations. Evol. Appl., 1: 95-111. Blackwell Publishing Ltd.

Anderson, B., Alexandersson, R. and Johnson, S.D. 2009. Evolution and coexistence of pollination ecotypes in an African Gladiolus (Iridaceae). Evolution (N. Y)., 64: 960-972. John Wiley \& Sons, Ltd.

Anderson, E. 1949. Introgressive Hybridization. New York: John, Wiley \& Sons.

Anderson, E. and Stebbins, G.L. 1954. Hybridization As an Evolutionary Stimulus. Evolution (N. Y)., 8: 378-388. Society for the Study of Evolution.

Andrew, R.L. and Rieseberg, L.H. 2013. Ddivergence is focused on few genomic regions early in speciation: incipient speciation of sunflower ecotypes.

Evolution (N. Y)., 67: 2468-2482. John Wiley \& Sons, Ltd.

Arnold, M.L. 1997. Natural Hybridization and Evolution. Oxford Series. New York.

Arnold, M.L. 1992. Natural hybridization as an evolutionary process.

Arntzen, J.W., Trujillo, T., Butôt, R., Vrieling, K., Schaap, O., Gutiérrez-

Rodríguez, J., et al. 2016. Concordant morphological and molecular clines in a contact zone of the Common and Spined toad (Bufo bufo and B. spinosus) in the northwest of France. Front. Zool., 13: 52. BioMed Central.

Baltisberger, M. and Hörandl, E. 2016. Karyotype evolution supports the molecular phylogeny in the genus Ranunculus (Ranunculaceae). Perspect. Plant Ecol. Evol. Syst., 18: 1-14. Elsevier GmbH.

Bankevich, A., Nurk, S., Antipov, D., Gurevich, A.A., Dvorkin, M., Kulikov, A.S., et al. 2012. SPAdes: A new genome assembly algorithm and its applications to single-cell sequencing. J. Comput. Biol., 19: 455-477. Mary Ann Liebert, Inc.

Barnard-Kubow, K.B., Debban, C.L. and Galloway, L.F. 2015. Multiple glacial refugia lead to genetic structuring and the potential for reproductive isolation in a herbaceous plant. Am. J. Bot., 102: 1842-1853. Wiley-Blackwell.

Barton, N. and Gale, K. 1993. Genetic analysis of hybrid zones [In: Hybrid zones 
and evolutionary process] (R. Harrison, ed). Oxford, UK: Oxford University Press.

Barton, N. and Hewitt, G.M. 1985. Analysis of Hybrid Zones. Annual Reviews.

Beaumont, M.A. and Balding, D.J. 2004. Identifying adaptive genetic divergence among populations from genome scans. Mol. Ecol., 13: 969-980. John Wiley \& Sons, Ltd.

Benson, L. 1948. A Treatise on the North American Ranunculi. Am. Midl. Nat., 40: 1. JSTOR.

Benson, L. 1954. Supplement to a Treatise on the North American Ranunculi. Am. Midl. Nat., 52: 328. JSTOR.

Berman, J., Sheng, Y., Gómez Gómez, L., Veiga, T., Ni, X., Farré, G., et al. 2016. Red Anthocyanins and Yellow Carotenoids Form the Color of OrangeFlower Gentian (Gentiana lutea L. var. aurantiaca). PLoS One, 11: e0162410. Public Library of Science.

Bolger, A.M., Lohse, M. and Usadel, B. 2014. Trimmomatic: a flexible trimmer for Illumina sequence data . Bioinformatics, 30: 2114-2120.

Bradbury, P.J., Zhang, Z., Kroon, D.E., Casstevens, T.M., Ramdoss, Y. and Buckler, E.S. 2007. TASSEL: software for association mapping of complex traits in diverse samples. Bioinformatics, 23: 2633-2635. Narnia.

Briggs, B.G. 1962. Interspecific hybridization in the Ranunculus lappaceus group. Evolution (N. Y)., 16: 372-390. Wiley.

Corlett, R.T. and Westcott, D.A. 2013. Will plant movements keep up with climate change? Elsevier Current Trends.

Derryberry, E.P., Derryberry, G.E., Maley, J.M. and Brumfield, R.T. 2014. Hzar: Hybrid zone analysis using an R software package. Mol. Ecol. Resour., 14: 652-663. Wiley/Blackwell (10.1111).

Ehleringer, J.R. and Mooney, H.A. 1978. Leaf Hairs: Effects on Physiological Activity and Adaptive Value to a Desert Shrub. Oecologia, 37: 183-200.

Elshire, R.J., Glaubitz, J.C., Sun, Q., Poland, J.A., Kawamoto, K., Buckler, E.S., et al. 2011. A Robust, Simple Genotyping-by-Sequencing (GBS) Approach for High Diversity Species. PLoS One, 6: e19379. Public Library of Science.

Esquerré, D., Ramírez-Álvarez, D., Pavón-Vázquez, C.J., Troncoso-Palacios, J., 
Garín, C.F., Keogh, J.S., et al. 2019. Speciation across mountains:

Phylogenomics, species delimitation and taxonomy of the Liolaemus leopardinus clade (Squamata, Liolaemidae). Mol. Phylogenet. Evol., 139: 106524. Academic Press.

Eugster, C.H. and Märki-Fischer, E. 1991. The Chemistry of Rose Pigments. Angew. Chemie Int. Ed. English, 30: 654-672. John Wiley \& Sons, Ltd.

Evanno, G., Reganaut, S. and Goudet, J. 2005. Detecting the number of clusters of individuals using the software structure: a simulation study. Mol. Ecol., 14: 2611-2620. John Wiley \& Sons, Ltd.

Excoffier, L. and Lischer, H.E.L. 2010. Arlequin suite ver 3.5: A new series of programs to perform population genetics analyses under Linux and Windows. Mol. Ecol. Resour., 10: 564-567. Blackwell Publishing Ltd.

Fitzpatrick, M.C. and Keller, S.R. 2015. Ecological genomics meets communitylevel modelling of biodiversity: mapping the genomic landscape of current and future environmental adaptation. Ecol. Lett., 18: 1-16. Blackwell Publishing Ltd.

Foll, M. and Gaggiotti, O. 2008. A genome-scan method to identify selected loci appropriate for both dominant and codominant markers: A Bayesian perspective. Genetics, 180: 977-993. Genetics.

Gay, L., Crochet, P.A., Bell, D.A. and Lenormand, T. 2008. Comparing clines on molecular and phenotypic traits in hybrid zones: A window on tension zone models. Evolution (N. Y)., 62: 2789-2806. Wiley/Blackwell.

Gompert, Z. and Buerkle, C.A. 2011. Bayesian estimation of genomic clines. Mol. Ecol., 20: 2111-2127. Wiley/Blackwell (10.1111).

Gompert, Z., Mandeville, E.G. and Buerkle, C.A. 2017. Analysis of Population Genomic Data from Hybrid Zones. Annu. Rev. Ecol. Evol. Syst., 48: 207229. Annual Reviews.

Goudet, J. 2005. hierfstat, a package for $r$ to compute and test hierarchical Fstatistics. Mol. Ecol. Notes, 5: 184-186. John Wiley \& Sons, Ltd (10.1111).

Grammatikopoulos, G. and Manetas, Y. 1994. Direct absorption of water by hairy leaves of Phlomis fruticosa and its contribution to drought avoidance. Can. J. Bot., 72: 1805-1811. Canadian Science Publishing.

Grotewold, E. 2006. The science of flavonoids. Springer New York. 
Guichoux, E., Garnier-Géré, P., Lagache, L., Lang, T., Boury, C. and Petit, R.J. 2013. Outlier loci highlight the direction of introgression in oaks. Mol. Ecol., 22: 450-462.

Harrison, R.G. and Larson, E.L. 2014. Hybridization, introgression, and the nature of species boundaries. J. Hered., 105: 795-809. Oxford University Press.

Heuertz, M., Fineschi, S., Anzidei, M., Pastorelli, R., Salvini, D., Paule, L., et al. 2004. Chloroplast DNA variation and postglacial recolonization of common ash (Fraxinus excelsior L.) in Europe. Mol. Ecol., 13: 3437-3452. John Wiley \& Sons, Ltd.

Hörandl, E., Paun, O., Johansson, J.T., Lehnebach, C., Armstrong, T., Chen, L., et al. 2005. Phylogenetic relationships and evolutionary traits in Ranunculus s.I. (Ranunculaceae) inferred from ITS sequence analysis. Mol. Phylogenet. Evol., 36: 305-327. Academic Press.

Howard, D.J., Preszler, R.W., Williams, J., Fenchel, S. and Boecklen, W.J. 1997. How Discrete are Oak Species? Insights from a Hybrid Zone Between Quercus grisea and Quercus gambelii. Evolution (N. Y)., 51: 747. JSTOR.

Janes, J.K., Miller, J.M., Dupuis, J.R., Malenfant, R.M., Gorrell, J.C., Cullingham, C.I., et al. 2017. The $\mathrm{K}=2$ conundrum. Mol. Ecol., 26: 3594-3602. Blackwell Publishing Ltd.

Johnsen, A., Kearns, A.M., Omland, K.E. and Anmarkrud, J.A. 2017. Sequencing of the complete mitochondrial genome of the common raven Corvus corax (Aves: Corvidae) confirms mitogenome-wide deep lineages and a paraphyletic relationship with the Chihuahuan raven C. cryptoleucus. PLoS One, 12: e0187316. Public Library of Science.

Jombart, T. 2008. adegenet: a R package for the multivariate analysis of genetic markers. Bioinformatics, 24: 1403-1405. Narnia.

Kagan, J., Vrilakas, S., Christy, J., Gaines, E., Wise, L., Pahl, C., et al. 2016. Rare, Threatened and Endangered Species of Oregon. Institute for Natural Resources.

Kálmán, K., Medvegy, A. and Mihalik, E. 2004. Pattern of the floral variation in the hybrid zone of two distylous Primula species. Flora, 199: 218-227. Elsevier $\mathrm{GmbH}$.

Karabourniotis, G., Papadopoulos, K., Papamarkou, M. and Manetas, Y. 1992. 
Ultraviolet-B radiation absorbing capacity of leaf hairs. Physiol. Plant., 86: 414-418. John Wiley \& Sons, Ltd.

Kay, G.M., Barton, P.S., Driscoll, D.A., Cunningham, S.A., Blanchard, W., McIntyre, S., et al. 2016. Incorporating regional-scale ecological knowledge to improve the effectiveness of large-scale conservation programmes. Anim. Conserv., 19: 515-525. Blackwell Publishing Ltd.

Kay, K.M., Woolhouse, S., Smith, B.A., Pope, N.S. and Rajakaruna, N. 2018. Sympatric serpentine endemic Monardella (Lamiaceae) species maintain habitat differences despite hybridization. Mol. Ecol., 27: 2302-2316. Blackwell Publishing Ltd.

Kohrn, B.F., Persinger, J.M. and Cruzan, M.B. 2017. An Efficient Pipeline to Generate Data for Studies in Plastid Population Genomics and Phylogeography. Appl. Plant Sci., 5: 1700053. Botanical Society of America.

Kopelman, N.M., Mayzel, J., Jakobsson, M., Rosenberg, N.A. and Mayrose, I. 2015. Clumpak: a program for identifying clustering modes and packaging population structure inferences across K. Mol. Ecol. Resour., 15: 11791191. John Wiley \& Sons, Ltd (10.1111).

Levin, D.A. 2003. The cytoplasmic factor in plant speciation. Syst. Bot., 28: 5-11. The American Society of Plant Taxonomists.

Li, H. and Durbin, R. 2009. Fast and accurate short read alignment with BurrowsWheeler transform. 25: 1754-1760.

Li, H., Handsaker, B., Wysoker, A., Fennell, T., Ruan, J., Homer, N., et al. 2009. The Sequence Alignment/Map format and SAMtools. Bioinforma. Appl. NOTE, 25: 2078-2079.

Li, T., Fu, X., Deng, H., Han, X., Wen, F. and Xu, L. 2019. The complete chloroplast genome of Ranunculus Cantoniensis. Mitochondrial DNA Part B, 4: 1095-1096. Taylor and Francis Ltd.

Lischer, H. and Excoffier, H. 2012. PGDSpider: an automated data conversion tool for connecting population genetics and genomics programs. Bioinformatics, 28: 289-299.

Lotsy, J. 1916. Evolution by Means of Hybridization. The Hague: Martinus Nijhoff.

Martin, L.J. and Cruzan, M.B. 1999. Patterns of hybridization in the Piriqueta caroliniana complex in central florida: evidence for an expanding hybrid 
zone. Evolution (N. Y)., 53: 1037-1049. Wiley/Blackwell (10.1111).

Martin, M. 2011. Cutadapt removes adapter sequences from high-throughput sequencing reads. EMBnet.journal, 17: 10. EMBnet Stichting.

Mayr, E. 1963. Animal species and evolution. Anim. species Evol. Harvard University Press; London: Oxford University Press.

Mayr, E. 1942. Systematics and the Origin of Species. New York: Columbia Univ. Press.

Meléndez-Ackerman, E.J. 1997. Patterns of color and nectar variation across an Ipomopsis (Polemoniaceae) hybrid zone. Am. J. Bot., 84: 41-47. Wiley.

Melo, A.T.O., Bartaula, R. and Hale, I. 2016. GBS-SNP-CROP: a referenceoptional pipeline for SNP discovery and plant germplasm characterization using variable length, paired-end genotyping-by-sequencing data. $B M C$ Bioinformatics, 17: 29. BioMed Central.

Morales-Rozo, A., Tenorio, E.A., Carling, M.D. and Cadena, C.D. 2017. Origin and cross-century dynamics of an avian hybrid zone. BMC Evol. Biol., 17: 257. BioMed Central.

Mori, M., Yoshida, K., Ishigaki, Y., Matsunaga, T., Nikaido, O., Kameda, K., et al. 2005. UV-B protective effect of a polyacylated anthocyanin, HBA, in flower petals of the blue morning glory, Ipomoea tricolor cv. Heavenly Blue. Bioorganic Med. Chem., 13: 2015-2020. Elsevier Ltd.

National Center for Biotechnology Information. 2019. Sequin.

Nosil, P., Funk, D.J. and Ortiz-Barrientos, D. 2009. Divergent selection and heterogeneous genomic divergence. John Wiley \& Sons, Ltd.

Ono, E., Fukuchi-Mizutani, M., Nakamura, N., Fukui, Y., Yonekura-Sakakibara, K., Yamaguchi, M., et al. 2006. Yellow flowers generated by expression of the aurone biosynthetic pathway. Proc. Natl. Acad. Sci. U. S. A., 103: 11075-11080. National Academy of Sciences.

Palmer, J.D. 1987. Chloroplast DNA evolution and biosystematic uses of chloroplast DNA variation. The University of Chicago PressThe American Society of Naturalists.

Palmer, J.D. 1992. Mitochondrial DNA in Plant Systematics: Applications and Limitations. In: Molecular Systematics of Plants, pp. 36-49. Springer US. 
Pansarin, E.R. and Amaral, M.C.E. 2008. Reproductive biology and pollination mechanisms of Epidendrum secundum (Orchidaceae). Floral variation: a consequence of natural hybridization? Plant Biol., 10: 211-219. John Wiley \& Sons, Ltd.

Petit, R.J., Duminil, R., Fineschi, S., Hampe, A., Salvini, D. and Vendramin, G.G. 2004. Comparative organization of chloroplast, mitochondrial and nuclear diversity in plant populations. Mol. Ecol., 14: 689-701. John Wiley \& Sons, Ltd (10.1111).

Picard ToolKit. 2019. Broad Institute, Github Repository.

Polechová, J. 2018. Is the sky the limit? On the expansion threshold of a species' range. PLoS Biol., 16: e2005372. Public Library of Science.

Pritchard, J.K., Stephens, M. and Donnelly, P. 2000. Inference of Population Structure Using Multilocus Genotype Data.

Puorto, G., Da Graça Salomão, M., Theakston, R.D.G., Thorpe, R.S., Warrell, D.A. and Wüster, W. 2001. Combining mitochondrial DNA sequences and morphological data to infer species boundaries: phylogeography of lanceheaded pitvipers in the Brazilian Atlantic forest, and the status of Bothrops pradoi (Squamata: Serpentes: Viperidae). J. Evol. Biol., 14: 527538. John Wiley \& Sons, Ltd.

Qi, Y., Lu, B., Gao, H., Hu, P. and Fu, J. 2014. Hybridization and mitochondrial genome introgression between Rana chensinensis and R. kukunoris. Mol. Ecol., 23: 5575-5588. Wiley/Blackwell.

Reich, D.E., Cargili, M., Boik, S., Ireland, J., Sabeti, P.C., Richter, D.J., et al. 2001. Linkage disequilibrium in the human genome. Nature, 411: 199-204. Nature Publishing Group.

Remington, C.L. 1968. Suture-Zones of Hybrid Interaction Between Recently Joined Biotas. In: Evolutionary Biology, pp. 321-428. Boston, MA: Springer US.

Riemsdijk, I. van, Arntzen, J.W., Bucciarelli, G., McCartney-Melstad, E., Rafajlović, M., Scott, P.A., et al. 2019. Spatial variation in introgression along a toad hybrid zone in France. bioRxiv, 746073. Cold Spring Harbor Laboratory.

Rieseberg, L.H. 1997. Hybrid origins of plant species. Annu. Rev. Ecol. Syst., 28: 359-389. Annual Reviews 4139 El Camino Way, P.O. Box 10139, Palo Alto, 
CA 94303-0139, USA.

Ripley, B.S., Pammenter, N.W. and Smith, V.R. 1999. Function of leaf hairs revisited: The hair layer on leaves Arctotheca populifolia reduces photoinhibition, but leads to higher leaf temperatures caused by lower transpiration rates. J. Plant Physiol., 155: 78-85. Elsevier GmbH.

Rognes, T., Flouri, T., Nichols, B., Quince, C. and Mahé, F. 2016. VSEARCH: A versatile open source tool for metagenomics. PeerJ, 2016: e2584. PeerJ Inc.

SAS. 2007. SAS/STAT user's guide version 9.1. Carey, North Carolina: SAS Institute.

Scott, P.A., Glenn, T.C. and Rissler, L.J. 2019. Formation of a recent hybrid zone offers insight into the geographic puzzle and maintenance of species boundaries in musk turtles. Mol. Ecol., 28: 761-771. Blackwell Publishing Ltd.

Skaltsa, H., Verykokidou, E., Harvala, C., Karabourniotis, G. and Manetasi, Y. 1994. UV-B protective potential and flavonoid content of leaf hairs of Quercus ilex. Phytochemistry, 37: 987-990. Pergamon.

Sobel, J.M. and Streisfeld, M.A. 2015. Strong premating reproductive isolation drives incipient speciation in Mimulus aurantiacus. Evolution (N. Y)., 69: 447-461. Society for the Study of Evolution.

Soltis, D.E., Gitzendanner, M.A., Strenge, D.D. and Soltis, P.S. 1997. Chloroplast DNA intraspecific phylogeography of plants from the Pacific Northwest of North America. Plant Syst. Evol., 206: 353-373. Springer-Verlag.

Stankowski, S., Sobel, J.M. and Streisfeld, M.A. 2017. Geographic cline analysis as a tool for studying genome-wide variation: a case study of pollinatormediated divergence in a monkeyflower. Mol. Ecol., 26: 107-122. Blackwell Publishing Ltd.

Sung, C.J., Bell, K.L., Nice, C.C. and Martin, N.H. 2018. Integrating Bayesian genomic cline analyses and association mapping of morphological and ecological traits to dissect reproductive isolation and introgression in a Louisiana Iris hybrid zone. Mol. Ecol., 27: 959-978. Wiley/Blackwell (10.1111).

Swenson, N.G. 2006. Gis-based niche models reveal unifying climatic mechanisms that maintain the location of avian hybrid zones in a North American suture zone. J. Evol. Biol., 19: 717-725. Wiley/Blackwell 
(10.1111).

Swenson, N.G. and Howard, D.J. 2004. Do suture zones exist? Evolution (N. Y)., 58: 2391-2397. Wiley/Blackwell (10.1111).

Taylor, S.A., Larson, E.L. and Harrison, R.G. 2015. Hybrid zones: Windows on climate change. Trends Ecol. Evol., 30: 398-406. Elsevier Current Trends.

Wang, L., Luzynski, K., Pool, J.E., Janoušek, V., Dufková, P., Vyskočilová, M.M., et al. 2011. Measures of linkage disequilibrium among neighbouring SNPs indicate asymmetries across the house mouse hybrid zone. Mol. Ecol., 20: 2985-3000. John Wiley \& Sons, Ltd.

Wyman, S.K., Jansen, R.K. and Boore, J.L. 2004. Automatic annotation of organellar genomes with DOGMA. Bioinforma. Appl. NOTE, 20: 3252-3255.

Zamudio, K.R. and Wieczorek, A.M. 2007. Fine-scale spatial genetic structure and dispersal among spotted salamander (Ambystoma maculatum) breeding populations. Mol. Ecol., 16: 257-274. John Wiley \& Sons, Ltd. 


\section{Appendix A. Haplotype Identification}

Samples from $14 R$. austro-oreganus, $14 R$. occidentalis, and 11 putative hybrid populations were collected throughout Jackson County, Oregon. Libraries, primarily with 20 individuals per population, were created using KAPA HyperPlus Library Preparation Kit. Samples were suspended in 10mM Tris- $\mathrm{HCl}$ and kept at $20^{\circ} \mathrm{C}$ until capture preparation, where a MyBaits capture array (Arbor Biosciences) to target specific regions that are conserved amongst $\sim 20$ full chloroplast genomes as described in Kohrn et al. (2017). The samples were transported on ice to Oregon Health and Science University (Portland, Oregon) where Illumina sequencing was used to obtain cpDNA for 46 Single Sample Libraries (SSLs) and 51 Pooled Population Libraries (PLs; Table A1).

Reference chloroplast genomes were constructed and annotated for both R. austro-oreganus (NCBI accession no. KX639503) and R. occidentalis (NCBI accession no. KX557270). Shotgun sequenced reads for both species were used to construct complete chloroplast genomes and adapters were trimmed using cutadapt v.1.1 (Martin, 2011) and trimmed for quality using Trimmomatic v.0.39 (Bolger et al., 2014). Ranunculus macranthas (NCBI accession no. NC_008796) was used for reference guided assembly, where bwa mem (Li and Durbin, 2009) was used to align the raw shotgun sequenced reads to the reference. The final $R$. occidentalis genome was used as the reference for the $R$. austro-oreganus 
genome assembly. Once the raw reads were mapped the reference, the reads were then filtered using SAMtools (Li et al., 2009). The sorted bam file was then converted to a fastq file using Picard Toolkit (2019). SPAdes (Bankevich et al., 2012) was then used to scaffold raw reads to for manual assembly. Error correction on the final circularized genome consisted of indexing the trimmed and filtered reads in order to re-align to the draft genome by utilizing bwa mem once again. Various SAMtools tools were then used to view the raw reads in comparison to the consensus read, and any discrepancies were fixed. DOGMA (Wyman et al., 2004) was then used to annotate the two finalized genomes and Sequin v.16.0 (National Center for Biotechnology Information, 2019) allowed for GenBank submission ready products.

Sequence reads were aligned to the $R$. occidentalis reference genome following the methods found in Kohrn et al. (2017). Genomic variants were identified within the chloroplast genome. The SNPs were filtered for quality and support. A total of 31 haplotypes were discovered across the putative hybrid zone (Fig. A1) with extensive haplotype sharing between the species (Fig. A2). 


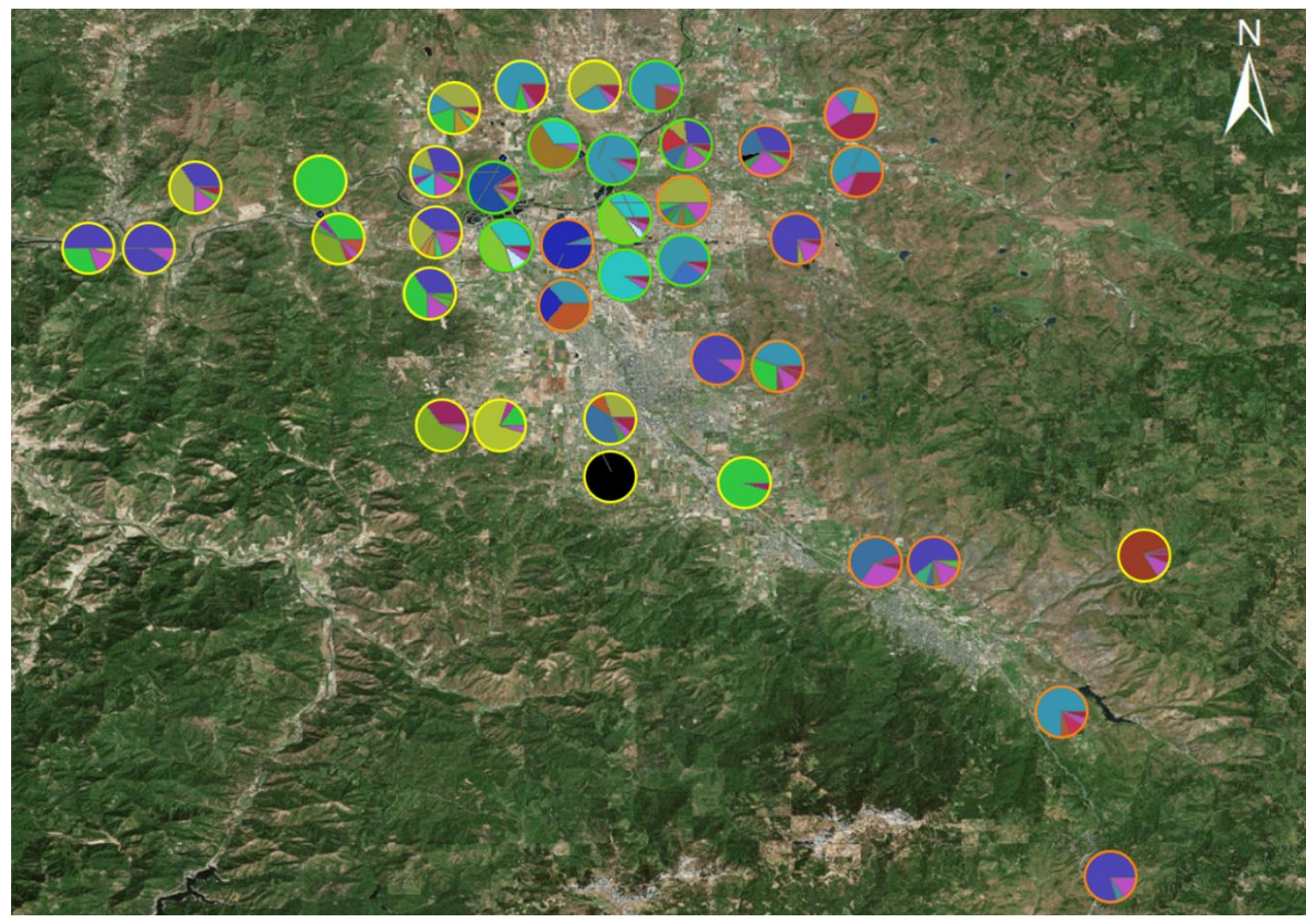

Figure A1. Haplotype frequencies belonging to each of the 51 populations across the putative hybrid zone. Pie charts are outlined in the corresponding species classification (Ranunculus occidentalis, yellow; $R$. austro-oreganus, orange; Putative Hybrids, green). 


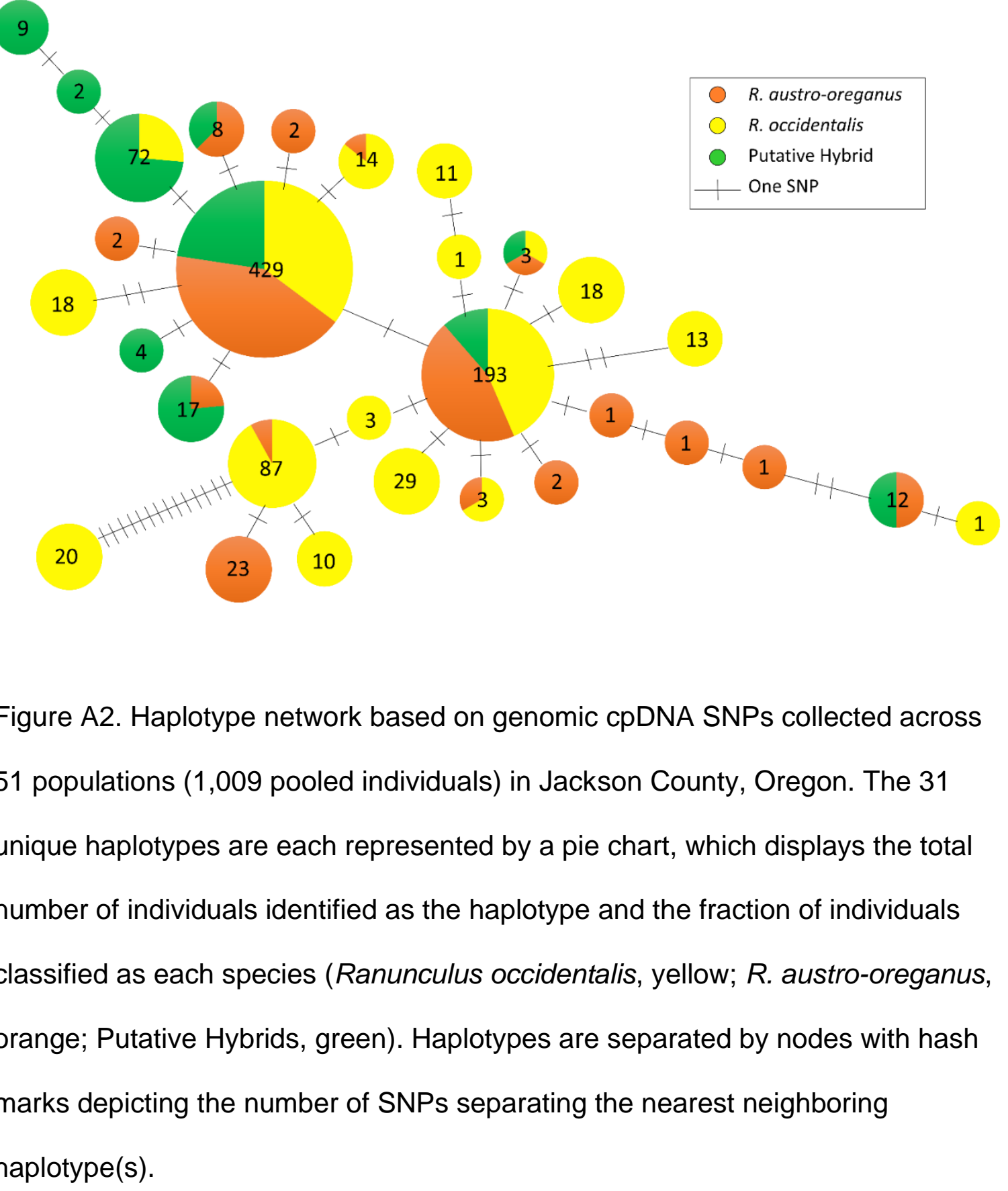


Table A1. Pooled populations (PLs) included in chloroplast sequencing where 20 individuals were pooled per population. The number of single sample

libraries (SSLs) processed from each population is listed in the last column.

\begin{tabular}{|c|c|c|c|c|c|}
\hline Location Name & Latitude & Longitude & Species & No. Individuals in Pool & No. SSLS \\
\hline AgateLake1 & 42.42131 & -122.77464 & Ranaus & 20 & 1 \\
\hline AgateLake2 & 42.41217 & -122.77715 & Ranaus & 20 & 2 \\
\hline Brownsboro1 & 42.46189 & -122.74269 & Ranaus & 20 & 1 \\
\hline Brownsboro2 & 42.46016 & -122.73991 & Ranaus & 20 & 1 \\
\hline ButteFallsBLM & 42.49589 & -122.69261 & Ranocc & 20 & 1 \\
\hline ChulaRock & 42.47684 & -122.83836 & Ranaus & 20 & 1 \\
\hline Dawgs & 42.46175 & -122.94286 & Hybrid & 20 & 2 \\
\hline Denman & 42.46143 & -122.88158 & Ranaus & 20 & 1 \\
\hline EaglePoint & 42.47236 & -122.79391 & Ranaus & 20 & 1 \\
\hline EmigrantLake & 42.14664 & -122.62058 & Ranaus & 20 & 1 \\
\hline Emu & 42.45259 & -123.00207 & Ranocc & 20 & 2 \\
\hline GlassLane & 42.50557 & -122.89159 & Ranocc & 20 & 1 \\
\hline GoldHill & 42.4357 & -123.05159 & Ranocc & 20 & 1 \\
\hline GrizzlyPeak & 42.2375 & -122.57323 & Ranocc & 20 & 0 \\
\hline Imperatrice1 & 42.23313 & -122.70831 & Ranaus & 20 & 1 \\
\hline Imperatrice2 & 42.23402 & -122.69521 & Ranaus & 20 & 1 \\
\hline JacksonvilleForkTrail & 42.31339 & -122.98202 & Ranocc & 20 & 0 \\
\hline JulietAve & 42.48932 & -122.87351 & Hybrid & 19 & 1 \\
\hline LaurelGlenCreek & 40.55361 & -122.45389 & Ranocc & 20 & 1 \\
\hline LowerRogueMountain & 42.41634 & -123.1547 & Ranocc & 20 & 0 \\
\hline LowerRogueSwitchback & 42.41631 & -123.15229 & Ranocc & 20 & 0 \\
\hline LTR1 & 42.46822 & -122.94569 & Ranocc & 20 & 1 \\
\hline LTR2 & 42.45583 & -122.952 & Ranocc & 0 & 1 \\
\hline LTR3 & 42.46069 & -122.94842 & Ranocc & 20 & 1 \\
\hline LTR4 & 42.45164 & -122.95132 & Ranocc & 20 & 1 \\
\hline NoRiverAccess & 42.44974 & -123.00276 & Ranocc & 20 & 1 \\
\hline OldStageRd1 & 42.39008 & -122.98995 & Ranocc & 20 & 1 \\
\hline OldStageRd2 & 42.42134 & -123.04127 & Ranocc & 20 & 1 \\
\hline PerryRd & 42.51147 & -122.9353 & Ranocc & 20 & 1 \\
\hline PhoenixWaterTower & 42.2793 & -122.80553 & Ranocc & 20 & 0 \\
\hline RogueSide & 42.4518 & -123.12539 & Ranocc & 20 & 0 \\
\hline RoxyAnn1 & 42.34795 & -122.78654 & Ranaus & 11 & 2 \\
\hline RoxyAnn2 & 42.35124 & -122.79394 & Ranaus & 20 & 1 \\
\hline SamsValleyPrivate & 42.49821 & -122.97446 & Ranocc & 19 & 0 \\
\hline SkyKing & 42.04928 & -122.59246 & Ranaus & 20 & 1 \\
\hline SurreyRoadNorth & 42.2866 & -122.88306 & Ranocc & 20 & 0 \\
\hline SurreyRoadSouth & 42.28329 & -122.88406 & Ranocc & 19 & 0 \\
\hline Touvelle & 42.44286 & -122.88145 & Ranaus & 20 & 1 \\
\hline UpperRiverRoad1 & 42.45661 & -123.02602 & Ranocc & 20 & 1 \\
\hline UpperRiverRoad2 & 42.45409 & -123.00842 & Ranocc & 20 & 1 \\
\hline UTR1 & 42.46838 & -122.88453 & Hybrid & 20 & 0 \\
\hline UTR2 & 42.4707 & -122.89983 & Hybrid & 11 & 1 \\
\hline UTR4 & 42.46797 & -122.89055 & Hybrid & 20 & 1 \\
\hline UTR6 & 42.46758 & -122.88822 & Hybrid & 20 & 1 \\
\hline UTR7 & 42.46665 & -122.88222 & Hybrid & 20 & 1 \\
\hline UTR8 & 42.47507 & -122.91609 & Hybrid & 20 & 1 \\
\hline UTR9 & 42.47011 & -122.91144 & Hybrid & 20 & 1 \\
\hline UTR-Radar & 42.47706 & -122.91624 & Hybrid & 20 & 1 \\
\hline UTR-West & 42.46593 & -122.91493 & Hybrid & 20 & 1 \\
\hline Whetstone & 42.41838 & -122.90896 & Ranaus & 20 & 1 \\
\hline Whetstone2 & 42.41227 & -122.91065 & Ranaus & 20 & 1 \\
\hline WhiskeyShastatownTrinity & 40.64819 & -122.57411 & Ranocc & 20 & 1 \\
\hline
\end{tabular}




\section{Appendix B. Nuclear DNA}

A

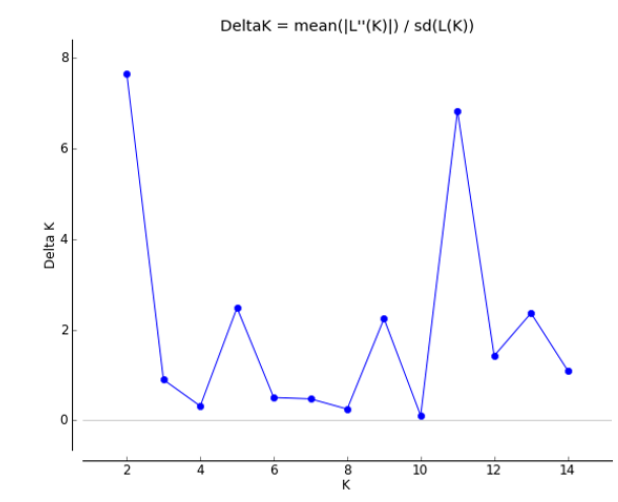

C

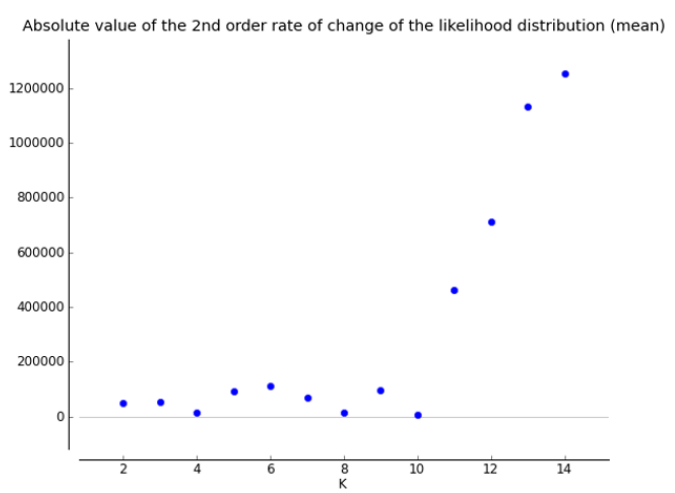

B

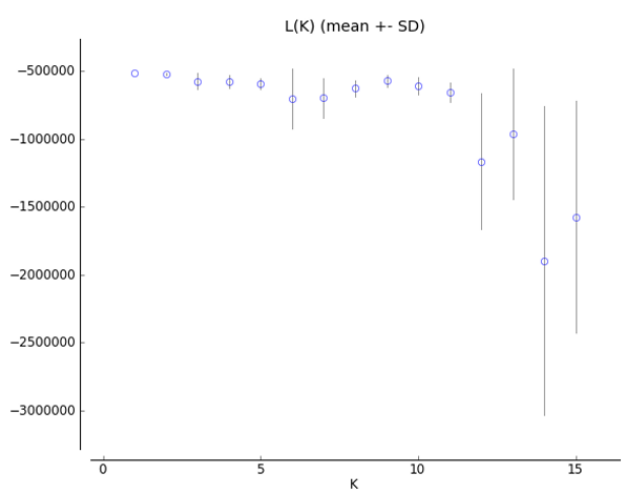

D

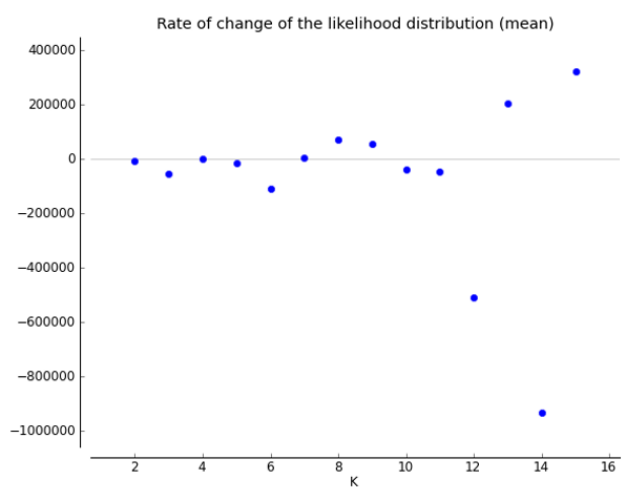

Figure B1. Genetic clustering approximated with Structure. A-D displays output statistics. Peaks in Delta $K$ value $(A)$ indicate optimum values of $K$. 

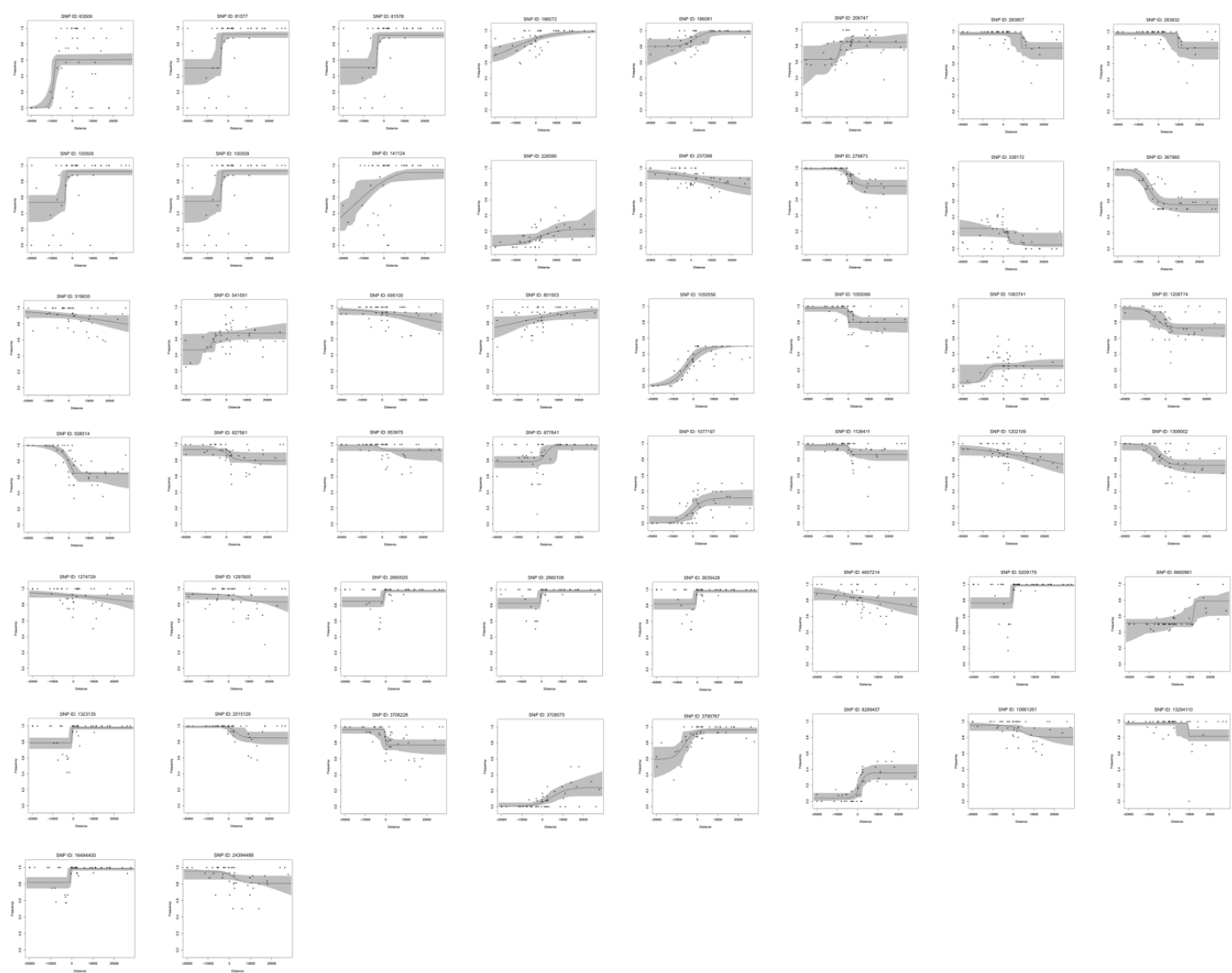

Figure B2. The 50 significant cline models from HZAR. Allelic frequency $(0-1)$ is measured on the $y$-axis and estimated for each population across geographic distance (meters; x-axis). 
Table B1. Sampling locations and number of individuals sequenced for GBS

analyses, ordered from East (negative values) to West (positive values) relative

to the proposed center of the contact zone (UTR9; PopID 33). Number of

significant loci pairs detected in each population in the linkage disequilibrium

\section{analysis are reported.}

\begin{tabular}{|c|c|c|c|c|c|c|c|}
\hline PopID & Location Name & Latitude & Longitude & Species & Distance (m) & No. Individuals Sampled & No. Sig. Loci Pairs \\
\hline 41 & LowerRogueMountain & 42.41634 & -123.15470 & Ranocc & -19952.34 & 7 & 2 \\
\hline 42 & LowerRogueSwitchback & 42.41631 & -123.15229 & Ranocc & -19754.67 & 8 & 2 \\
\hline 43 & RogueSide & 42.45180 & -123.12539 & Ranocc & -17548.32 & 8 & 40 \\
\hline 17 & GoldHill & 42.43570 & -123.05159 & Ranocc & -11495.20 & 8 & 6 \\
\hline 11 & OldStageRd2 & 42.42134 & -123.04127 & Ranocc & -10648.74 & 8 & 21 \\
\hline 37 & UpperRiverRd1 & 42.45661 & -123.02602 & Ranocc & -9397.93 & 8 & 28 \\
\hline 38 & UpperRiverRoad2 & 42.45409 & -123.00842 & Ranocc & -7954.36 & 8 & 12 \\
\hline 36 & NoRiverAccess & 42.44974 & -123.00276 & Ranocc & -7490.13 & 8 & 62 \\
\hline 7 & OldStageRd1 & 42.39008 & -122.98995 & Ranocc & -6439.44 & 8 & 30 \\
\hline 40 & JacksonvilleForkTrail & 42.31339 & -122.98202 & Ranocc & -5789.02 & 8 & 6 \\
\hline 45 & BrittCanyonTrail & 42.31303 & -122.97759 & Ranocc & -5425.67 & 8 & 8 \\
\hline 32 & SamsValleyPrivate & 42.49821 & -122.97446 & Ranocc & -5168.94 & 8 & 25 \\
\hline 28 & LTR4 & 42.45164 & -122.95132 & Ranocc & -3270.98 & 8 & 26 \\
\hline 39 & LTR3 & 42.46069 & -122.94842 & Ranocc & -3033.12 & 8 & 25 \\
\hline 27 & LTR1 & 42.46822 & -122.94569 & Ranocc & -2809.21 & 8 & 22 \\
\hline 13 & Dawgs & 42.46143 & -122.88158 & Hybrid & -2577.09 & 8 & 46 \\
\hline 25 & PerryRoad & 42.51147 & -122.93530 & Ranocc & -1957.01 & 8 & 33 \\
\hline 19 & UTR-Radar & 42.47706 & -122.91624 & Hybrid & -393.70 & 8 & 8 \\
\hline 34 & UTR8 & 42.47507 & -122.91609 & Hybrid & -381.40 & 8 & 18 \\
\hline 22 & UTR-West & 42.46593 & -122.91493 & Hybrid & -286.25 & 8 & 10 \\
\hline 33 & UTR9 & 42.47011 & -122.91144 & Hybrid & 0.00 & 8 & 31 \\
\hline 10 & Whetstone2 & 42.41227 & -122.91065 & Ranaus & 64.80 & 8 & 34 \\
\hline 12 & Whetstone1 & 42.41838 & -122.90896 & Ranaus & 203.41 & 7 & 20 \\
\hline 9 & UTR2 & 42.47070 & -122.89983 & Hybrid & 952.26 & 8 & 13 \\
\hline 14 & GlassLane & 42.50557 & -122.89159 & Ranocc & 1628.11 & 8 & 9 \\
\hline 3 & UTR4 & 42.46797 & -122.89055 & Hybrid & 1713.41 & 8 & 27 \\
\hline 30 & UTR6 & 42.46758 & -122.88822 & Hybrid & 1904.52 & 8 & 15 \\
\hline 46 & SurreyRoadSouth & 42.28329 & -122.88406 & Ranocc & 2245.73 & 7 & 34 \\
\hline 44 & SurreyRoadNorth & 42.28660 & -122.88306 & Ranocc & 2327.75 & 8 & 26 \\
\hline 31 & UTR7 & 42.46665 & -122.88222 & Hybrid & 2396.64 & 8 & 26 \\
\hline 2 & Denman1 & 42.46175 & -122.94286 & Ranaus & 2449.14 & 8 & 12 \\
\hline 21 & TouvelleStatePark & 42.44286 & -122.88145 & Ranaus & 2459.80 & 8 & 41 \\
\hline 29 & JulietAve & 42.48932 & -122.87351 & Hybrid & 3111.04 & 8 & 48 \\
\hline 8 & ChulaRockRd & 42.47684 & -122.83836 & Ranaus & 5994.07 & 8 & 27 \\
\hline 47 & PheonixWaterTower & 42.27930 & -122.80553 & Ranocc & 8686.81 & 8 & 18 \\
\hline 24 & RoxyAnn2 & 42.35124 & -122.79394 & Ranaus & 9637.43 & 8 & 19 \\
\hline 15 & EaglePointHill & 42.47236 & -122.79391 & Ranaus & 9639.89 & 8 & 14 \\
\hline 1 & RoxyAnn1 & 42.34795 & -122.78654 & Ranaus & 10244.38 & 8 & 25 \\
\hline 35 & AgateLake2 & 42.41217 & -122.77715 & Ranaus & 11014.56 & 8 & 16 \\
\hline 20 & AgateLake1 & 42.42131 & -122.77464 & Ranaus & 11220.43 & 8 & 40 \\
\hline 4 & Brownsboro1 & 42.46189 & -122.74269 & Ranaus & 13840.99 & 8 & 63 \\
\hline 5 & Brownsboro2 & 42.46016 & -122.73991 & Ranaus & 14069.00 & 8 & 48 \\
\hline 18 & Imperatrice1 & 42.23313 & -122.70831 & Ranaus & 16660.86 & 8 & 42 \\
\hline 23 & Imperatrice2 & 42.23402 & -122.69521 & Ranaus & 17735.33 & 7 & 32 \\
\hline 48 & ButteFalls & 42.49589 & -122.69261 & Ranocc & 17948.58 & 8 & 34 \\
\hline 6 & EmigrantLake & 42.14664 & -122.62058 & Ranaus & 23856.52 & 8 & 19 \\
\hline 16 & SkyKingCole & 42.04928 & -122.59246 & Ranaus & 26162.94 & 8 & 6 \\
\hline 26 & GrizzlyPeak & 42.23750 & -122.57323 & Ranocc & 27740.20 & 8 & 26 \\
\hline
\end{tabular}


Table B2. Outlier loci listed in ascending order by locus ID that were identified by moderate allelic frequency differences $(>0.3)$ and their corresponding cline center relative to the proposed center and cline width estimates from HZAR.

\begin{tabular}{|c|c|c|}
\hline Locus ID & Cline Center (m) & Cline Width (m) \\
\hline 63509 & -8531 & 3758 \\
\hline 81577 & -3284 & 84 \\
\hline 81578 & -3272 & 140 \\
\hline 100508 & -3305 & 165 \\
\hline 100509 & -3262 & 82 \\
\hline 141124 & -14686 & 41672 \\
\hline 186072 & -10428 & 36486 \\
\hline 186081 & 1661 & 11566 \\
\hline 206747 & -3623 & 2001 \\
\hline 226590 & 768 & 19576 \\
\hline 237266 & 14951 & 74044 \\
\hline 279873 & 1702 & 6356 \\
\hline 283807 & 9263 & 174 \\
\hline 283832 & 9493 & 163 \\
\hline 319835 & 29876 & 100197 \\
\hline 338172 & 2464 & 3527 \\
\hline 367960 & -5218 & 10224 \\
\hline 508514 & 2268 & 11602 \\
\hline 541591 & -6679 & 4123 \\
\hline 695100 & 28338 & 77793 \\
\hline 801503 & -20143 & 83682 \\
\hline 827561 & 1235 & 7478 \\
\hline 853875 & -1134 & 4062 \\
\hline 877641 & 3698 & 5780 \\
\hline 1050556 & -3286 & 14206 \\
\hline 1055099 & 16 & 109 \\
\hline 1063741 & -9396 & 4666 \\
\hline 1077197 & -503 & 12381 \\
\hline 1126411 & 554 & 1805 \\
\hline 1202109 & 27387 & 96144 \\
\hline 1208774 & -4840 & 10340 \\
\hline 1274729 & 54796 & 139669 \\
\hline 1297605 & 6706 & 9059 \\
\hline 1309002 & -3851 & 11371 \\
\hline 1323135 & -646 & 256 \\
\hline 2015129 & 3451 & 7502 \\
\hline 2660025 & -895 & 137 \\
\hline 2660108 & -379 & 110 \\
\hline 3635428 & -527 & 212 \\
\hline 3706228 & -350 & 93 \\
\hline 3708575 & 4573 & 15733 \\
\hline 3790767 & -6361 & 9246 \\
\hline 4657214 & 20153 & 121159 \\
\hline 5209179 & -816 & 773 \\
\hline 6660961 & 11827 & 1488 \\
\hline 8289457 & 1210 & 5062 \\
\hline 10861261 & 3647 & 9778 \\
\hline 13294110 & 9194 & 151 \\
\hline 16494400 & -542 & 244 \\
\hline 24394488 & 2215 & 8388 \\
\hline
\end{tabular}

